\title{
Area-Selective Deposition of Ruthenium by Area-Dependent Surface Diffusion
}

\section{Journal Article}

\section{Author(s):}

Grillo, Fabio (D); Soethoudt, Job; Marques, Esteban A.; de Martín, Lilian; Van Dongen, Kaat; van Ommen, J. Ruud; Delabie, Annelies

Publication date:

2020-11-24

Permanent link:

https://doi.org/10.3929/ethz-b-000458713

Rights / license:

Creative Commons Attribution-NonCommercial-NoDerivatives 4.0 International

Originally published in:

Chemistry of Materials 32(22), https://doi.org/10.1021/acs.chemmater.0c02588 


\title{
Area-Selective Deposition of Ruthenium by Area-Dependent Surface Diffusion
}

\author{
Fabio Grillo,* Job Soethoudt,* Esteban A. Marques, Lilian de Martín, Kaat Van Dongen,
} J. Ruud van Ommen, and Annelies Delabie

Cite This: Chem. Mater. 2020, 32, 9560-9572

Read Online

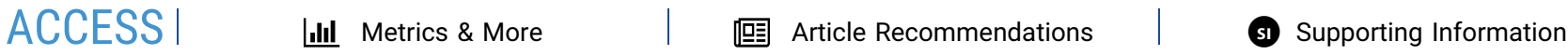

ABSTRACT: Area-selective deposition (ASD) enables the growth of materials on target regions of patterned substrates for applications in fields ranging from microelectronics to catalysis. Selectivity is often achieved through surface modifications aimed at suppressing or promoting the adsorption of precursor molecules. Here, we show instead that varying the surface composition can enable ASD by affecting surface diffusion rather than adsorption. $\mathrm{Ru}$ deposition from (carbonyl)-(alkylcyclohexadienyl) $\mathrm{Ru}$ and $\mathrm{H}_{2}$ produces smooth films on metal nitrides, and nanoparticles on $\mathrm{SiO}_{2}$. The latter form by surface diffusion and aggregation of $\mathrm{Ru}$ adspecies. Kinetic modeling shows that changing the surface termination of $\mathrm{SiO}_{2}$ from $-\mathrm{OH}$ to $-\mathrm{CH}_{3}$, and thus its surface energy, leads to larger and fewer nanoparticles because of a 1000-

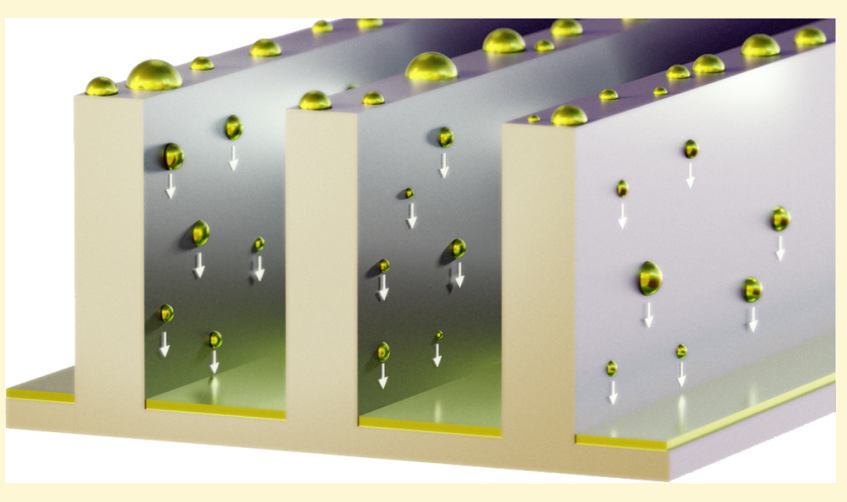
fold increase in surface diffusion rates. Kinetic Monte Carlo simulations show that even surface diffusion alone can enable ASD because adspecies tend to migrate from high- to low-diffusivity regions. This is corroborated by deposition experiments on threedimensional (3D) $\mathrm{TiN}-\mathrm{SiO}_{2}$ nanopatterns, which are consistent with $\mathrm{Ru}$ migrating from $\mathrm{SiO}_{2}$ to TiN. Such insights not only have implications for the interpretation of experimental results but may also inform new ASD protocols, based on chemical vapor and atomic layer deposition, that take advantage of surface diffusion.

\section{INTRODUCTION}

Area-selective deposition (ASD) is becoming an increasingly promising approach for the precise fabrication of composite nanostructured materials for applications in fields ranging from nanoelectronics to catalysis. ${ }^{1-9}$ Unlike conventional deposition techniques, which are designed to achieve uniform deposition over large areas, ASD enables the growth of materials only on target areas, the so-called growth surfaces, while avoiding deposition on nontarget areas, the nongrowth surfaces. To date, ASD can be achieved through different approaches, many of which rely on the combined use of surface modifications and vapor phase deposition techniques such as chemical vapor deposition (CVD) $)^{10-13}$ and atomic layer deposition (ALD). ${ }^{4,14,15}$

Surface modifications are typically aimed at suppressing the adsorption of precursor molecules on nongrowth surfaces. ${ }^{16-27}$ However, the growth and morphology of deposits are not dictated by adsorption alone but are rather a result of the competition between adsorption, surface diffusion, and aggregation of adspecies $^{28-31}$ (Figure 1). Yet, quantifying the extent to which surfaces and surface modifications affect each of these processes remains challenging. ${ }^{2,32-38}$

Surface diffusion, in particular, offers an often-overlooked avenue to enhance selectivity. It is known, for example, that in selective epitaxial growth of semiconductors, adatoms can migrate from the nongrowth surface to the growth surface, if they bind more strongly with the latter. ${ }^{39}$ As a result, the boundaries between growth and nongrowth surfaces can effectively limit nanoparticle formation on nontarget areas by capturing adatoms diffusing from the nongrowth surface. More generally, the notion of suppressing nanoparticle formation by adatom capture goes back to the early treatments of the atomistic theory of thin film growth. ${ }^{2,40,41}$ Nanoparticles themselves, by capturing diffusing adatoms, suppress the formation of new nanoparticles in their neighborhood. In fact, the distance between nanoparticles in the early stages of growth provides a measure of the diffusion length of adatoms. ${ }^{29}$

Surface diffusion plays an especially important role in the growth of high-surface-energy materials such as ruthenium on low-surface-energy substrates such as $\mathrm{SiO}_{2}$, as diffusion allows

Received: June 19, 2020

Revised: October 21, 2020

Published: November 6, 2020 


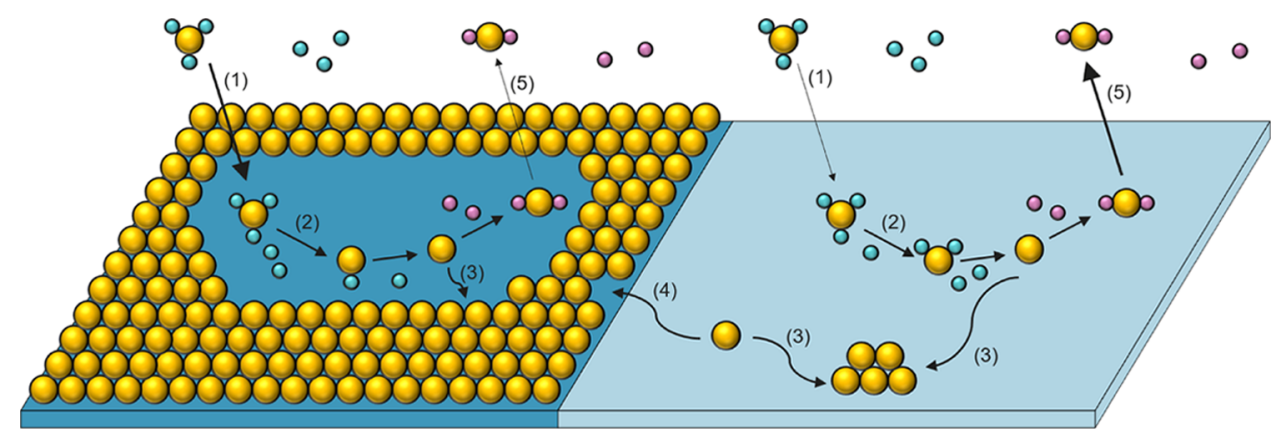

Figure 1. Processes involved in ASD: (1) adsorption, (2) surface reaction, (3) surface diffusion and aggregation, (4) exchange between growth and nongrowth surfaces, and (5) desorption. The growth surface is indicated in dark blue, the nongrowth surface in light blue, and the deposited material in yellow. Turquoise and pink indicate ligands or reactants that take part in surface reactions but are not part of the deposited material.
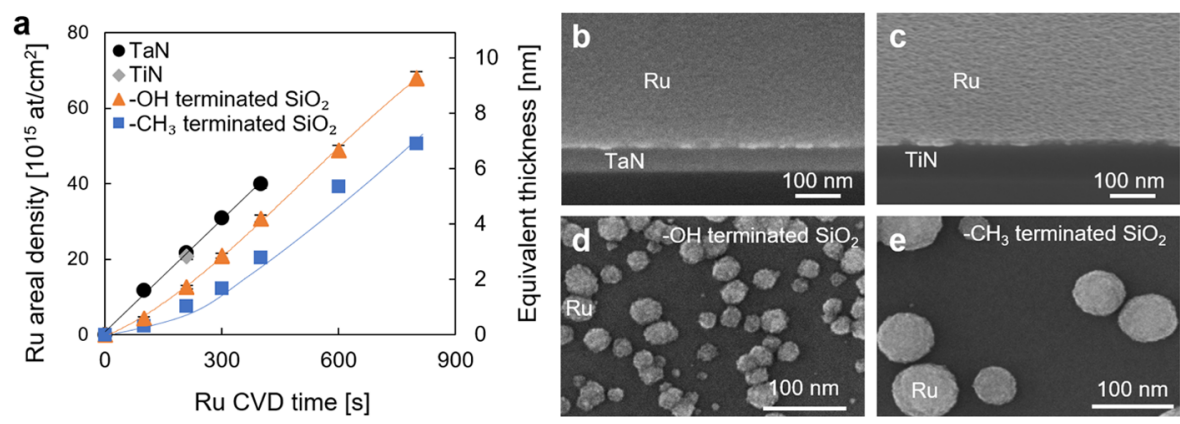

Figure 2. Amount of Ru deposited by Ru CVD at $250{ }^{\circ} \mathrm{C}$ and morphology of the deposits on different substrates. (a) Evolution of the amount of $\mathrm{Ru}$ deposited with time, as measured by Rutherford backscattering spectrometry (RBS). The equivalent Ru layer thickness assuming bulk density is shown on the right axis. Lines are provided as a guide to the eye. (b-e) Scanning electron microscopy (SEM) micrographs of Ru deposits on TaN, TiN, and $-\mathrm{OH}$ - and $-\mathrm{CH}_{3}$-terminated $\mathrm{SiO}_{2}$. The amount of $\mathrm{Ru}$ on each surface corresponds to approximately $2 \times 10^{16}$ atom $\mathrm{cm}^{-2} \mathrm{Ru}$ as measured by RBS. This corresponds to $210 \mathrm{~s}$ of $\mathrm{Ru} \mathrm{CVD}$ on $\mathrm{TaN}$ and $\mathrm{TiN}, 300 \mathrm{~s}$ on $-\mathrm{OH}$-terminated $\mathrm{SiO}_{2}$, and $400 \mathrm{~s}$ on $-\mathrm{CH}_{3}$-terminated $\mathrm{SiO}$.

deposits to aggregate and thus minimize the total surface energy. $^{31,32,42-44}$ ASD of $\mathrm{Ru}$ on metal or nitride growth surfaces, in the presence of dielectric nongrowth surfaces, has been attracting considerable interest given its potential for sub$10 \mathrm{~nm}$ interconnect structures for nano-electronic devices, ${ }^{4-50}$ where $\mathrm{Ru}$ outperforms $\mathrm{Cu}$ in terms of both resistance and reliability. ${ }^{51} \mathrm{Ru}$ ASD also holds promise for the fabrication of hardmasks for patterning, ${ }^{48}$ bimetallic core-shell nanoparticles for heterogeneous catalysis, ${ }^{52}$ and oxidation-resistant conductive capping layers. ${ }^{53}$ The role of surface diffusion in the growth of $\mathrm{Ru}$ on dielectrics is particularly nuanced because, as we showed in a recent work, ${ }^{32}$ also small $\mathrm{Ru}$ nanoparticles, not only adatoms, can undergo diffusion and aggregation. However, a detailed understanding of how different surfaces and surface modifications affect the interplay between adsorption and surface diffusion is still lacking.

Here, we demonstrate that area-dependent surface diffusion can enable ASD. We do so by quantifying the surface dependence of adsorption and diffusion rates during (carbonyl)-(alkylcyclohexadienyl) $\mathrm{Ru} / \mathrm{H}_{2} \mathrm{CVD}$ through a joint computational and experimental approach. We capture the effect of surface composition on growth kinetics by linking well-defined atomistic mechanisms to the time evolution of experimental observables such as the size distribution of $\mathrm{Ru}$ nanoparticles and their number density and the amount of Ru deposited per unit area. Kinetic modeling of our experiments shows that changing the surface termination of $\mathrm{SiO}_{2}$ from $-\mathrm{OH}$ to $-\mathrm{CH}_{3}$ affects the growth kinetics by affecting surface diffusion rather than adsorption. Informed by the importance of surface diffusion in $\mathrm{Ru}$ CVD, we run kinetic Monte Carlo (KMC) simulations to study the effect of area-dependent diffusion rates and find that even differences in diffusion rates alone can lead to ASD. This is because adatoms and small nanoparticles tend to migrate from high- to low-diffusivity regions, where they remain kinetically trapped. To test this mechanism, we conduct experiments on $\mathrm{SiO}_{2} / \mathrm{TiN}$ three-dimensional (3D) nanopatterns with lateral dimensions comparable to the diffusion length of $\mathrm{Ru}$ adspecies. Indeed, we find that more $\mathrm{Ru}$ is deposited on the TiN surfaces in the nanopatterns than on the blankets. This suggests that $\mathrm{Ru}$ adspecies migrate from $\mathrm{SiO}_{2}$ to TiN surfaces, contributing to the selective growth of $\mathrm{Ru}$ films on the latter.

\section{RESULTS AND DISCUSSION}

Surface-Dependent Growth. First, we investigate the surface-dependent growth behavior of (carbonyl)(alkylcyclohexadienyl) Ru/ $\mathrm{H}_{2} \mathrm{CVD}$ at $250{ }^{\circ} \mathrm{C}$ on four different surfaces of well-known compositions: TiN, TaN, $-\mathrm{OH}-$ terminated $\mathrm{SiO}_{2}$, and $-\mathrm{CH}_{3}$-terminated $\mathrm{SiO}_{2}$. The TiN surface displays a native oxide as it is deposited ex situ, ${ }^{54}$ while $\mathrm{TaN}$ does not display a native oxide as it is deposited in the same apparatus used for $\mathrm{Ru} \mathrm{CVD}$. The $-\mathrm{OH}$-terminated $\mathrm{SiO}_{2}$ was obtained by plasma-enhanced atomic layer deposition (PEALD) and is characterized by a surface density of hydroxyl groups $(-\mathrm{OH})$ of $2.5 \mathrm{~nm}^{-2}$. The $-\mathrm{CH}_{3}$-terminated $\mathrm{SiO}_{2}$ surface was instead obtained by a self-limiting reaction of dimethylamino-trimethylsilane (DMA-TMS) with PEALD $\mathrm{SiO}_{2}$, which saturates the surface with $6-\mathrm{CH}_{3}$ groups $\mathrm{nm}^{-2} \cdot 19$

The starting surface has a marked impact on the amount of $\mathrm{Ru}$ deposited over time as well as on the morphology of the 

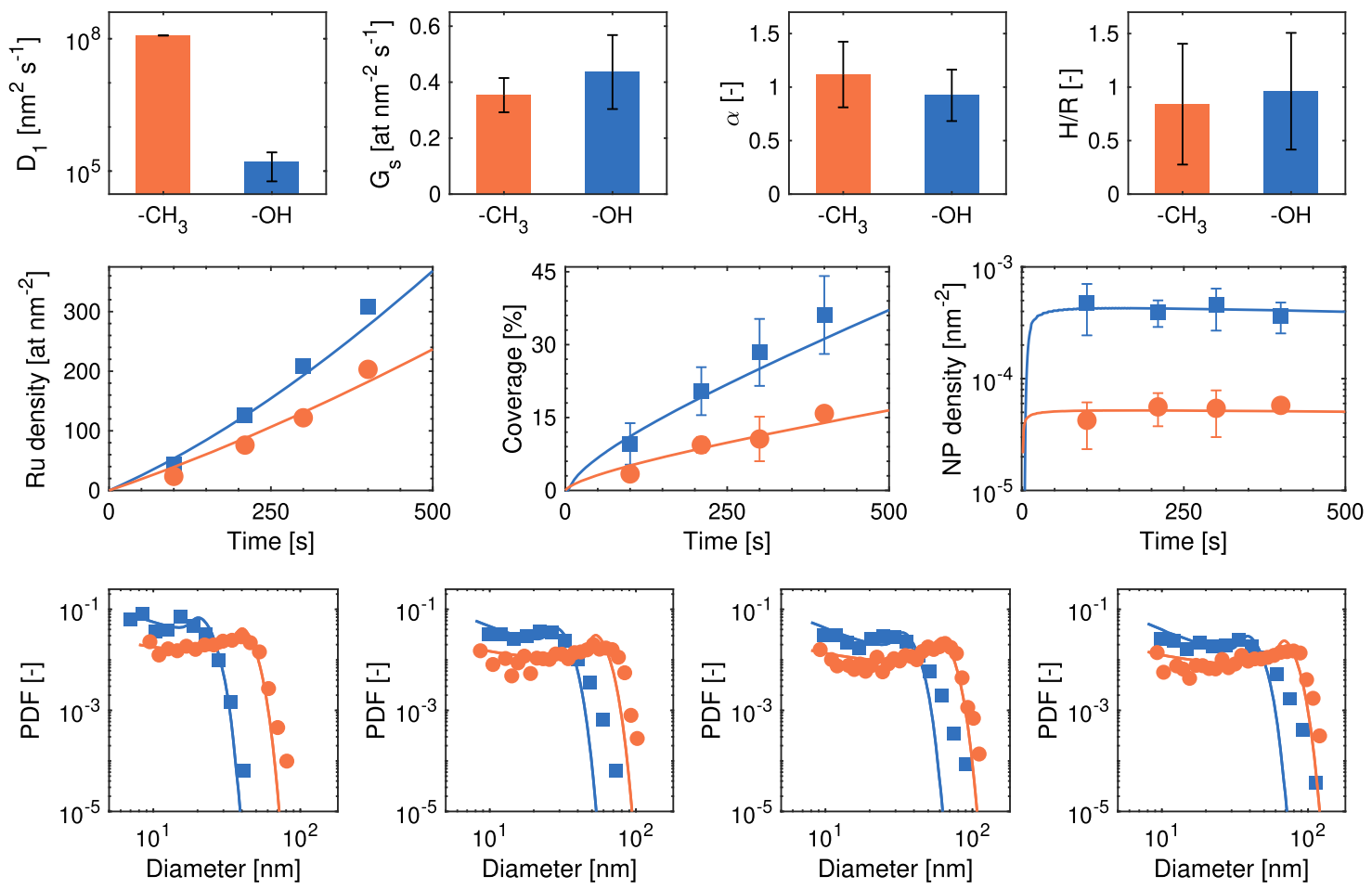

Figure 3. Comparison between simulation and experiments for $\mathrm{Ru} \mathrm{CVD}$ at $250{ }^{\circ} \mathrm{C}$ on $-\mathrm{OH}$-terminated (blue) and $-\mathrm{CH}_{3}$-terminated (red) $\mathrm{SiO}$. (a) Fitted parameters $D_{1}, \alpha, G_{s}$, and $\mathrm{H} / \mathrm{R}$ and their respective $95 \%$ confidence intervals for the two surface terminations. (b) Ru areal density as measured by RBS. (c) Areal coverage. (d) Nanoparticle density. (e) Size distribution of the nanoparticles expressed in terms of the probability density function (PDF) at different times: 100, 210, 300, and $400 \mathrm{~s}$, from left to right. Lines and symbols indicate simulated and experimental data, respectively. Size distributions, coverages, and number densities are obtained by SEM. The simulated observables are rescaled to account for the fact that nanoparticles smaller than a certain threshold $(\sim 5 \mathrm{~nm})$ could not be imaged or counted.

deposits (Figure 2). The amount of Ru deposited on $\mathrm{TiN}$ and $\mathrm{TaN}$ grows linearly over $400 \mathrm{~s}$ of deposition time (Figure 2a). Scanning electron microscopy (SEM) micrographs show that a film forms already within the first $210 \mathrm{~s}$ of deposition on both $\mathrm{TiN}$ and $\mathrm{TaN}$ (Figure $2 \mathrm{~b}, \mathrm{c}$ ). We can therefore estimate a steady-state $\mathrm{Ru}$-on-Ru growth rate of $\sim 0.95$ atom $\mathrm{nm}^{-2} \mathrm{~s}^{-1}$ from the slope of the $\mathrm{Ru}$ areal density over the $210-400 \mathrm{~s}$ time window. On the other hand, $\mathrm{Ru} \mathrm{CVD}$ on $-\mathrm{OH}$ - and $-\mathrm{CH}_{3}-$ terminated $\mathrm{SiO}_{2}$ surfaces is initially characterized by a low growth rate, which gradually approaches the steady-state value (0.95 atom nm $\mathrm{nm}^{-2} \mathrm{~s}^{-1}$ ). The initial inhibition is particularly pronounced on $-\mathrm{CH}_{3}$-terminated $\mathrm{SiO}_{2}$, as the amount of $\mathrm{Ru}$ deposited after $300 \mathrm{~s}$ is about half that deposited on $-\mathrm{OH}$ terminated $\mathrm{SiO}_{2}$ over the same period.

The nature of the surface also affects the degree of aggregation of the deposited $\mathrm{Ru}$. Smooth films with a thickness of $2-3 \mathrm{~nm}$ are observed after depositing $2 \times 10^{16}$ atom $\mathrm{cm}^{-2}$ of $\mathrm{Ru}$ on $\mathrm{TiN}$ and $\mathrm{TaN}$. In contrast, the same amount of $\mathrm{Ru}$ forms into clusters or nanoparticles (NPs) on $-\mathrm{OH}$ - and $-\mathrm{CH}_{3}$-terminated $\mathrm{SiO}_{2}$. In particular, the NPs are not only large compared to the thickness of the films deposited on TiN and $\mathrm{TaN}(2-3 \mathrm{~nm})$, given their average diameters of $28 \mathrm{~nm}(\sigma$ $=14 \mathrm{~nm})$ and $60 \mathrm{~nm}(\sigma=24 \mathrm{~nm})$ on $-\mathrm{OH}-$ and $-\mathrm{CH}_{3}-$ terminated $\mathrm{SiO}_{2}$, after 300 and $400 \mathrm{~s}$, respectively (Figure 2de), but also present broad size distributions with long tails on the large-size side (Figure $3 \mathrm{e}$ ).

The formation of such large NPs suggests that diffusion and aggregation play an important role in the early stages of growth on $-\mathrm{OH}$ - and $-\mathrm{CH}_{3}$-terminated $\mathrm{SiO}_{2}$. In fact, if the NPs nucleated at surface defects and grew by precursor adsorption alone, their size should be much smaller. The contribution to the radial growth of the NPs from precursor adsorption can be estimated from the steady-state $\mathrm{Ru}$-on- $\mathrm{Ru}$ growth rate $(0.95$ atom $\left.\mathrm{nm}^{-2} \mathrm{~s}^{-1}\right)$ by considering that the average thickness of a monolayer $(\mathrm{ML})$ of $\mathrm{Ru}$ is $\overline{h^{\mathrm{ML}}}=\left(\frac{\mathrm{MW}}{\rho N_{\mathrm{A}}}\right)^{1 / 3} \cong 0.24 \mathrm{~nm}$ and that the corresponding areal density is $\overline{c^{\mathrm{ML}}}=\left(\frac{\rho N_{\mathrm{A}}}{\mathrm{MW}}\right)^{2 / 3} \cong 17.6$ atom $\mathrm{nm}^{-2}$, where $\rho$ is the bulk density, MW is the molecular weight, and $N_{\mathrm{A}}$ is the Avogadro number. ${ }^{55}$ The radial growth rate due to adsorption is then $\cong 0.95 \frac{\overline{h^{\mathrm{ML}}}}{c^{\mathrm{ML}}} \cong 0.013 \mathrm{~nm} \mathrm{~s}^{-1}$. Such a radial growth rate would translate into NPs with a diameter of $\sim 8 \mathrm{~nm}$ after $300 \mathrm{~s}$ (cf. $28 \mathrm{~nm}$ on $-\mathrm{OH}$-terminated $\mathrm{SiO}_{2}$ ) and of $\sim 10 \mathrm{~nm}$ after $400 \mathrm{~s}$ (cf. $60 \mathrm{~nm}$ on $-\mathrm{CH}_{3}$-terminated $\mathrm{SiO}_{2}$ ). Therefore, precursor adsorption cannot account for the observed average sizes and certainly cannot explain the formation of NPs as large as $100 \mathrm{~nm}$ that make up the long tails of the size distributions.

The aggregation of metals on low-surface-energy dielectrics is well documented and is ascribed to differences in surface energy between the metal adlayer and the dielectric substrate. ${ }^{31,32,44,56}$ Because metal adatoms bond more strongly with each other than they do with the underlying dielectric, they agglomerate into large particles to minimize the metal surface area. Nonetheless, metal thin films can still form on high-surface-energy substrates such as nitrides and metals. Ru displays a surface energy of $3 \mathrm{~J} \mathrm{~m}^{-2}$, which is comparable to $2 \mathrm{~J}$ $\mathrm{m}^{-2}$ of TiN and $\mathrm{TaN}$ but much greater than $0.05 \mathrm{~J} \mathrm{~m}^{-2}$ of $-\mathrm{OH}$-terminated $\mathrm{SiO}_{2}{ }^{57-59}$ or $0.03 \mathrm{~J} \mathrm{~m}^{-2}$ of the $-\mathrm{CH}_{3}$ terminated $\mathrm{SiO}_{2}$ used in this study (see the Experimental and Computational Methods section). 
While TaN was deposited in the same cluster where $\mathrm{Ru}$ CVD was performed, without breaking the vacuum, TiN was deposited ex situ and might therefore present a native oxide layer. As a result, the actual surface energy of the TiN substrates used here might be closer to that of $\mathrm{TiO}_{2}(0.3-1.1 \mathrm{~J}$ $\left.\mathrm{m}^{2}\right)^{60}$ than to that of pristine $\mathrm{TiN}\left(2 \mathrm{~J} \mathrm{~m}^{-2}\right)$. Nonetheless, the surface energy of $\mathrm{TiO}_{2}$ is still one to two orders of magnitude higher than that of the $\mathrm{SiO}_{2}$ substrates. Therefore, it is not surprising that $\mathrm{Ru} C \mathrm{CVD}$ yields layer-by-layer growth on $\mathrm{TiN}$ and $\mathrm{TaN}$ and island growth on $-\mathrm{OH}$ - and $-\mathrm{CH}_{3}$-terminated $\mathrm{SiO}_{2}$.

The low surface energy of $-\mathrm{CH}_{3}$-terminated $\mathrm{SiO}_{2}$ compared to that of $-\mathrm{OH}$-terminated $\mathrm{SiO}_{2}$ can also explain the formation of larger NPs and the lower particle density on the former. However, to what extent the surface termination affects adsorption, diffusion, and aggregation and how this in turn affects the growth rate remain outstanding questions that we seek to answer through computational modeling.

Modeling Island Growth on $\mathrm{SiO}_{2}$. To quantify the relative importance of adsorption and surface diffusion during $\mathrm{Ru} \mathrm{CVD}$ on $\mathrm{SiO}_{2}$ and the effect of surface termination, we linked experimental observables to atomistic mechanisms through a rate-equation mean-field modeling approach that builds on the theory of nucleation and growth of thin films. ${ }^{28,41,61-64}$ This model is a variant of the ones developed in our previous works ${ }^{31,32,34}$ for island growth in ALD of noble metals. The model consists of a population balance that takes into account the rate at which adatoms and clusters of atoms, or nanoparticles, are generated and consumed by elementary processes. Here, the term nanoparticles denotes any cluster comprising a number of $\mathrm{Ru}$ atoms $k>1$.

To strike a balance between the explanatory power of the model and the number of unknown parameters, we made several simplifying assumptions. Given the relatively low deposition temperature $\left(250{ }^{\circ} \mathrm{C}\right)$ and the high bond energy of $\mathrm{Ru}$, we assume that the smallest stable nucleus is a dimer $(k$ $=2$ ), aggregation is irreversible, and desorption of $\mathrm{Ru}$ adatoms is negligible. ${ }^{28,31,34,41}$ By disregarding the possibility that atoms can detach from nanoparticles, we also neglect the role of Ostwald ripening (OR): the growth of large particles at the expense of small ones via an exchange of single atoms driven by size-dependent differences in chemical potential (GibbsThomson effect). ${ }^{28}$

We believe that Ostwald ripening cannot explain our observations for a number of reasons. OR can be surfacemediated or gas-phase-mediated depending on whether the exchange of single atoms takes place through surface diffusion or via evaporation and condensation. ${ }^{44,65,66}$ Surface-mediated OR is inherently surface-dependent and may in principle explain the different trends observed here for different surfaces. However, surface-mediated OR requires overcoming the energy barrier set by the detachment of a $\mathrm{Ru}$ atom from a nanoparticle and its adsorption on the substrate. ${ }^{65,67}$ Because of the strong $\mathrm{Ru}-\mathrm{Ru}$ bond and the weak binding of noble metals such as $\mathrm{Ru}$ with $\mathrm{SiO}_{2}$, surface-mediated OR is unlikely to be the dominant mechanism. ${ }^{65,68}$ Gas-phase-mediated OR, on the other hand, requires the volatilization of $\mathrm{Ru}$ species and is thus not expected to be much affected by the nature of the substrate. ${ }^{65}$ Furthermore, in both cases, mean-field and kinetic Monte Carlo simulations show that OR in concomitance with a constant influx of adatoms should lead to left-skewed and increasingly narrower size distributions, ${ }^{34,69}$ which is the opposite of what we observe: broad and increasingly broader distributions with long tails on the large-size side (Figure 3e). Finally, both theoretical and experimental works overwhelmingly show that Ostwald ripening is indeed an important coarsening mechanism for supported nanoparticles but at high temperatures $\left(\sim 400-1000{ }^{\circ} \mathrm{C}\right)$ and on long timescales (several hours to years), whereas our experiments were carried out at relatively low temperatures $\left(250{ }^{\circ} \mathrm{C}\right)$ and on short timescales of the order of minutes. ${ }^{65,70-73}$

We also do not model the role of surface defects in an explicit fashion. Contrary to our observations, if surface defects acted as preferential nucleation sites ${ }^{74}$ and behaved as traps from which nanoparticles cannot escape, the nanoparticles should present very narrow size distributions. ${ }^{75}$ Furthermore, if adsorption took place only at surface defects, precursor adsorption alone cannot account for the formation of the large nanoparticles observed here, as already mentioned above. Hence, we maintain that a minimal model of our experiment can neglect the role of surface defects but should certainly account for surface diffusion and aggregation of adatoms and nanoparticles. Nonetheless, if adatoms and nanoparticles can detach from surface defects and the trapping time distribution has a finite variance, ${ }^{76}$ then the role of defects can still be captured, albeit in a phenomenological fashion, by an effective diffusion coefficient and an effective adsorption rate. This is because higher concentrations of defects can be correlated with lower diffusion coefficients and higher adsorption rates. ${ }^{77,78}$

We therefore model the formation and growth of nanoparticles by taking into account the following processes: (i) adsorption of species containing one atom of Ru (adatoms) on the bare substrate and on $\mathrm{Ru}$ nanoparticles, (ii) diffusion of adatoms and nanoparticles, and (iii) binary collision and instantaneous aggregation of adatoms and nanoparticles.

This model translates into the following infinite set of nonlinear differential equations

$$
\begin{aligned}
\frac{\mathrm{d} n_{1}}{\mathrm{~d} t}= & G_{\mathrm{s}}\left(1-\sum_{k} n_{k} \pi r_{k}^{2}\right)-n_{1} \sum_{k} K_{1 k} n_{k} \\
\frac{\mathrm{d} n_{k}}{\mathrm{~d} t}= & G_{\mathrm{p}}\left(A_{k-1} n_{k-1}-A_{k} n_{k}\right)+\frac{1}{2} \sum_{i+j=k} K_{i j} n_{i} n_{j}-n_{k} \\
& \sum_{i} K_{k i} n_{i}
\end{aligned}
$$

Equations 1 and 2 describe the evolution in time of the average areal density of adatoms $n_{1}$ (atom area ${ }^{-1}$ ) and nanoparticles $n_{k}$ $\left(\operatorname{area}^{-1}\right)$, respectively. The first term on the right-hand side (rhs) of eq 1 describes the creation of adatoms due to precursor adsorption on the bare substrate (free from nanoparticles), whereas the second term captures the disappearance of adatoms due to their collision and aggregation with other diffusing species. Here, $G_{s}$ (atom time $\left.\mathrm{area}^{-1}\right)$ is the adsorption rate on the bare substrate, $r_{k}$ (length) is the projected radius of a nanoparticle comprising $k$ atoms, and $K_{1 k}$ is the aggregation kernel prescribing the rate at which adatoms collide and aggregate with other adatoms and nanoparticles of size $k$ to form nanoparticles of $k+1$ atoms.

The first term on the rhs of eq 2 is the net rate of formation of nanoparticles of $k$ atoms as a result of the deposition of a single $\mathrm{Ru}$ atom on the surface of nanoparticles of size $k-1$ and $k$. $G_{\mathrm{p}}$ (atom time $\mathrm{area}^{-1}$ ) is the adsorption rate of $\mathrm{Ru}$ atoms on the exposed surface area of the nanoparticles $A_{k}$ (area). The second term on the rhs of eq 2 is the rate of 
formation of nanoparticles of $k$ atoms due to the collision and aggregation of adspecies of sizes $i$ and $j$ such that $i+j=k$. Finally, the last term on the rhs of eq 2 is the rate of disappearance of nanoparticles of size $k$ due to their collision and aggregation with other adspecies.

The $K_{i j}$ terms are calculated using the self-consistent method proposed by Hubartt et al. ${ }^{79}$ for irreversible island growth with cluster diffusion as $K_{i j}=\sigma_{i} D_{i}+\sigma_{j} D_{j}$, where $D_{i}$ and $\sigma_{i}$ are the diffusion coefficient and the so-called capture number of a cluster of size $i$, respectively. The capture numbers are slowvarying correction factors that account for the fact that, by capturing adatoms and other clusters in their vicinity, clusters introduce local gradients in $n_{k}$, thus effectively creating depletion zones, which depend on their size as compared to the average diffusion length $\lambda$ (or capture length), at each given time. The capture numbers therefore allow one to reconcile the diffusion problem at the nanoparticle scale with the global mean-field balance defined by eqs 1 and 2. As prescribed by Hubartt et al., ${ }^{79}$ we calculate the capture numbers at each time step by solving the coupled equations $\lambda^{-2}=\sum_{i} \sigma_{i} n_{i}$ and $\sigma_{i}=\frac{2 \pi r_{i}}{\lambda} K_{1}\left(\frac{r_{i}}{\lambda}\right) / K_{0}\left(\frac{r_{i}}{\lambda}\right)$, where $K_{0}$ and $K_{1}$ are the modified Bessel functions of orders zero and one, respectively. This approach enables the estimation of size distributions and coverages that are in good agreement with KMC simulations. $^{32,79}$

We assume the diffusion coefficients to follow the power law: $D_{k}=D_{1} k^{-\alpha}$, where $D_{1}$ is the diffusion coefficient of adatoms and $\alpha$ is a scaling exponent. Such a law provides a good approximation for several adlayer-substrate systems. ${ }^{31,43,63,64,77,80-83}$ To calculate the projected radius and the surface area of the clusters, we model them as spherical caps ${ }^{44}$ characterized by a contact angle $\theta=2 \tan ^{-1}(\mathrm{H} / \mathrm{R})$, where $\mathrm{H} / \mathrm{R}$ is the height-to-radius ratio. We therefore let $r_{k}=S$ $k^{1 / 3}$, where $S$ is a shape factor that is a function of $\theta$ and the atomic volume $\Omega$

$$
S=\sin \theta \sqrt[3]{\frac{3 \Omega}{\pi\left(2-3 \cos \theta+\cos ^{3} \theta\right)}}
$$

Accordingly, we calculate $A_{k}$ as the exposed area of the spherical cap, which is the total area of the cap minus the area in contact with the substrate

$$
A_{k}=4 \pi\left(\frac{3 \Omega}{\pi\left(2-3 \cos \theta+\cos ^{3} \theta\right)}\right)^{2 / 3}\left(\frac{1-\cos \theta}{2}\right)
$$

It is worth noting that for hemispherical caps $(H / R=1, \theta=$ $\left.90^{\circ}\right) A_{k}=2 \pi r_{k}^{2}$ and $r_{k}=\sqrt[3]{\frac{3 \Omega k}{2 \pi}}$.

Equations 1 and 2 should in principle be solved for each $k \geq$ 1 up to a $k_{\max }$ such that $r_{\mathrm{k}_{\max }} \gg R_{\max }^{\exp }$, where $R_{\max }^{\exp }$ is the radius of the largest NP observed in the experiments. However, because the observed NPs are as large as several tens of nanometers and the number of atoms comprising an NP scales quickly with size $\left(k \sim R^{3}\right)$, this would translate into the solution of a prohibitively large number of equations, on the order of $10^{6}-$ $10^{8}$. To circumvent this, we divided the discrete domain of number densities $\left\{n_{k}\right\}_{k=1}^{k=k_{\max }}$ into a set of subdomains $\left\{N_{1}, \ldots, N_{\max }\right\}$ such that $N_{i}=\sum_{i}^{i+}{ }^{\Delta i} n_{i}$. In other words, $N_{i}$ is the total number density of clusters comprising a number of atoms between $i$ and $i+\Delta i$. Equations 1 and 2 are then recast in terms of $N_{i}$ and solved for each pivot $i$ using the discretization method proposed by Kumar and Ramkrishna, ${ }^{84-86}$ such that mass (total number of atoms) and number density are preserved.

To reduce drastically the number of equations to be solved, we construct the grid of pivots $i$ according to a geometric progression such that $i_{m+1} / i_{m}=\rho$, with $\rho>1$. The increments between pivots are therefore not constant and increase proportionally with the pivot values: $\Delta i_{m}=i_{m+1}-i_{m}=i_{m}(\rho$ - 1). Such a nonuniform grid, fine at small sizes and progressively coarser at large sizes, reflects the fact that the size distributions arising from dynamic aggregation tend to vary more rapidly at small sizes than they do in the limit of large sizes. In addition, to take into account that the size distribution evolves over time, we recalculate the grid at each time step using the moving pivot approach proposed by Kumar and Ramkrishna. ${ }^{85}$ By letting $\rho=1.2$ and the initial $i_{1}=1$, we can cover a range of sizes that is experimentally relevant with only over a hundred equations. This particular value of $\rho$ was chosen because reducing it further did not result in significant changes in the estimated number densities, as compared with the actual solutions of eqs 1 and 2 for $\left\{n_{k}\right\}_{k=1}^{k=k_{\max }}$.

The population balance written in terms of $N_{i}$ was solved together with all of the accompanying equations with the ode15s solver of MATLAB for stiff differential equations. The average number densities $\overline{n_{m}}$ corresponding to each $N_{m}$ were estimated as $\overline{n_{m}}=N_{m} / \Delta i_{m}$. The size distribution in terms of probability density was then calculated as $\overline{f_{m}}=\overline{n_{m}} / \sum_{m} N_{m}$. To compare the latter to the experimental data, we affected a change of variable and obtained the size distribution in terms of the projected radii of the NPs as $f_{r}=3 r^{2} / S^{3} f_{\mathrm{m}}\left(r^{3} / S^{3}\right)$, given that $f_{m} \mathrm{~d} m=f_{r} \mathrm{~d} r$, where $f_{\mathrm{m}}$ was constructed by shapepreserving piecewise cubic interpolation of $\overline{f_{m}}$. The other experimental observables that are estimated with the model are the $\mathrm{Ru}$ density (atom area $\left.{ }^{-1}\right) M(t)=\sum_{k} n_{k}(t) k$, the coverage (area/area) $Z(t)=\sum_{k} n_{k}(t) \pi r_{k}^{2}(t)$, and the total NP density $\left(\right.$ area $\left.^{-1}\right) n_{\text {tot }}(t)=\sum_{k} n_{k}(t)$.

The predictions of the model depend on five parameters describing the deposition rate on the substrate $\left(G_{s}\right)$ and on the nanoparticles $\left(G_{\mathrm{p}}\right)$, the diffusion rate of adatoms and nanoparticles $\left(D_{1}\right.$ and $\left.\alpha\right)$, and the shape of the nanoparticles $(\mathrm{H} / \mathrm{R})$. However, unless specified otherwise, the analysis presented here is based on the fitting of only four parameters $\left(G_{s}, D_{1}, \alpha\right.$, and H/R) because we expect $G_{\mathrm{p}}$ to be $\sim 0.95$ atom $\mathrm{nm}^{-2} \mathrm{~s}^{-1}$, which is the steady-state $\mathrm{Ru}$-on- $\mathrm{Ru}$ growth rate, which we measured independently. Nonetheless, as we will explain later, letting $G_{\mathrm{p}}$ be a fitting parameter has no significant impact on the estimates of the other parameters and thus on the overall analysis. The parameters of the model are assumed to be constant throughout the duration of the experiments. In particular, the value of $G_{s}$ is here regarded as a phenomenological measure of the rate of adsorption of the precursor on the bare substrates. The four parameters were estimated by fitting the mean-field (MF) model to an extensive body of experimental data (Figure 3), encompassing the evolution with time of the NP size distribution, Ru density, coverage, and NP density. The best fit for $\mathrm{Ru} \mathrm{CVD}$ on $-\mathrm{OH}$ - and $-\mathrm{CH}_{3}$ terminated $\mathrm{SiO}_{2}$ was found by varying the parameters and solving the population balance in an iterative fashion to minimize the discrepancy between observation and prediction. This was done by minimizing the objective function

$$
\phi\left(G_{\mathrm{s}}, D_{1}, \alpha, \mathrm{H} / \mathrm{R}\right)=\mathrm{e}^{M\left|\ln \left(y_{i}^{\mathrm{sim}} / y_{i}^{\mathrm{exp}}\right)\right|}-1
$$


using the Nelder-Mead simplex algorithm through the fminsearch function of MATLAB, where $M$ is the median and $y_{i}^{\text {sim }}$ and $y_{i}^{\exp }$ are the values of the predicted and experimental observables, respectively. The objective function thus formulated is also known as the median symmetric accuracy, ${ }^{87}$ which is a robust, unbiased, and scale-free error metric that allows one to compare data spanning different orders of magnitude.

Differences in Surface Diffusion Rates Best Explain the Effect of Surface Termination. By fitting the mean-field model to the experimental data shown in Figure 3, we find that the different growth kinetics on $-\mathrm{OH}$ - and $-\mathrm{CH}_{3}$-terminated $\mathrm{SiO}_{2}$ are best explained by a significant difference in surface diffusion rates. Over a time window of $400 \mathrm{~s}$, more $\mathrm{Ru}$ is deposited on $-\mathrm{OH}$-terminated $\mathrm{SiO}_{2}$. On the other hand, while the nanoparticles present very broad size distributions with similar shapes on both surfaces, their average size is consistently larger on $-\mathrm{CH}_{3}$-terminated $\mathrm{SiO}_{2}$ by approximately a factor of two. Nonetheless, despite the presence of larger nanoparticles, the coverage on $-\mathrm{CH}_{3}$-terminated $\mathrm{SiO}_{2}$ is lower because the nanoparticle density is about ten times smaller than the one on $-\mathrm{OH}$-terminated $\mathrm{SiO}_{2}$. In sum, less metal is deposited over $-\mathrm{CH}_{3}$-terminated $\mathrm{SiO}_{2}$ in the form of fewer nanoparticles with a broader size distribution. The MF model gives an excellent description of these trends with comparable growth parameters for both surfaces, except for $D_{1}$, which we estimate being three orders of magnitude higher on $-\mathrm{CH}_{3}$ terminated $\mathrm{SiO}_{2}$. Note that agreement between the model and experiments deteriorates for deposition times $>100 \mathrm{~s}$ for $-\mathrm{OH}$ terminated $\mathrm{SiO}_{2}$. In particular, the model underestimates the tail on the large-size side of the size distributions. This is expected because the mean-field approximation starts to break at coverages greater than $\cong 10-15 \%$ when static coalescence becomes important and the positions of the nanoparticles become highly correlated.

Assuming that the diffusion of adatoms can be described as a hopping process in two-dimensional $(2 \mathrm{D}),{ }^{88}$ we can estimate the effective energy barrier for diffusion $E_{\text {diff }}$ by letting $D_{1}=\frac{v_{0} l^{2}}{4} \mathrm{e}^{-E_{\text {diff }} / k_{\mathrm{b}} T}$, where $v_{0}$ is the vibration frequency, $l$ is the jump length, $k_{\mathrm{b}}$ is the Boltzmann constant, and $T$ is the deposition temperature. By assuming typical values for $v_{0} \sim$ $10^{13} \mathrm{~s}^{-1}$ and $l \sim 0.3 \mathrm{~nm}$, we estimate $E_{\text {diff }}$ to be $\sim 0.3$ and $\sim 0.6$ $\mathrm{eV}$ on $-\mathrm{CH}_{3}$ - and $-\mathrm{OH}$-terminated $\mathrm{SiO}_{2}$, respectively. This is in agreement with $-\mathrm{OH}$-terminated $\mathrm{SiO}_{2}$ having higher surface energy, which possibly entails a stronger $\mathrm{Ru}$-substrate bond and thus higher migration energy. ${ }^{44}$

We estimate $G_{s}$ being $\sim 25 \%$ higher on $-\mathrm{OH}$-terminated $\mathrm{SiO}_{2}\left(0.44 \pm 0.13\right.$ atom $\left.\mathrm{nm}^{-2} \mathrm{~s}^{-1}\right)$ than on $-\mathrm{CH}_{3}$-terminated $\mathrm{SiO}_{2}\left(0.35 \pm 0.06\right.$ atom nm$\left.{ }^{-2} \mathrm{~s}^{-1}\right)$; however, this difference is well within the margin of error. Therefore, a slightly lower adsorption rate on $\mathrm{CH}_{3}$-terminated $\mathrm{SiO}_{2}$ may contribute to a lower overall deposition rate, but it cannot explain the difference in the NP density and size. Furthermore, it is worth noting that such $G_{\mathrm{s}}$ values are $\sim 2$ to 3 times smaller than the $\mathrm{Ru}$-on-Ru steady-state growth rate. By varying $G_{s}$ in the range $0.3-0.6$ atom $\mathrm{nm}^{-2} \mathrm{~s}^{-1}$, while keeping the other parameters constant, we find that while $G_{s}$ does affect the amount of $\mathrm{Ru}$ deposited, it has little to no effect on the predicted size distribution and NP density (Figure S1).

To test further whether surface-dependent adsorption rates can explain the experimental observations, we also relaxed the constraint on $G_{\mathrm{p}}$. By fitting the latter along with the other parameters, we find $G_{\mathrm{p}}=0.97 \pm 0.29$ atom $\mathrm{nm}^{-2} \mathrm{~s}^{-1}$ for $-\mathrm{CH}_{3}$-terminated $\mathrm{SiO}_{2}$ and $G_{\mathrm{p}}=0.86 \pm 0.10$ atom $\mathrm{nm}^{-2} \mathrm{~s}^{-1}$ -OH-terminated $\mathrm{SiO}_{2}$, in remarkable agreement with the $\mathrm{Ru}$ on-Ru steady-state growth rate of 0.95 atom $\mathrm{nm}^{-2} \mathrm{~s}^{-1}$. Furthermore, by varying $G_{\mathrm{p}}$ in the range $0-2$ atom $\mathrm{nm}^{-2}$ $\mathrm{s}^{-1}$, while letting the other parameters constant, we find that even large variations in $G_{\mathrm{p}}$ cannot explain the different growth kinetics in that $G_{\mathrm{p}}$ mostly affects the amount of $\mathrm{Ru}$ deposited while having little to no effect on the NP density and size distribution. Therefore, surface-dependent adsorption rates cannot explain the different growth kinetics on different surface terminations.

We also find a scaling exponent of the nanoparticle mobility in the range $\alpha \sim 0.8-1.4$ for both $\mathrm{SiO}_{2}$ surfaces. These values agree with our previous analysis of $\mathrm{Ru}$ ALD on organosilicate glass, where experiments were best explained for $\alpha \geq 1$. In particular, they are compatible with at least two microscopic mechanisms of nanoparticle motion: edge evaporation/ condensation $(\alpha=1)$ and 2D diffusion $(\alpha=4 / 3) .{ }^{82}$ Finally, our analysis also suggests that differences in the shape of the nanoparticles cannot account for the different growth kinetics, as good agreement with experiments is found in both cases for $\mathrm{H} / \mathrm{R} \sim 1$, suggesting that the nanoparticles can be well approximated by hemispherical caps.

The lower $\mathrm{Ru}$ density on $-\mathrm{CH}_{3}$-terminated $\mathrm{SiO}_{2}$ is best explained by higher diffusion rates, causing a greater degree of metal aggregation and thus a lower available metal surface area, which in turn translates into a lower overall growth rate because $G_{\mathrm{p}}>G_{\mathrm{s}}{ }^{34}$ In fact, the nanoparticle density remains approximately constant on both surfaces, while being one order of magnitude lower on $-\mathrm{CH}_{3}$-terminated $\mathrm{SiO}_{2}$, throughout the experimental window explored here (100$400 \mathrm{~s}$ ). The number density reaches a plateau when a balance is stricken between adsorption and aggregation, that is, when all of the deposited atoms are captured by pre-existing nanoparticles. In such a dynamic steady state, the formation of new nanoparticles is balanced by coalescence and the average distance between the nanoparticles remains approximately equal to the average diffusion length $\lambda^{29}$

Now that we have established the importance of surface diffusion in $\mathrm{Ru}$ CVD on dielectrics, and how surface termination can have a dramatic impact on it, we consider its implications for ASD. By estimating the diffusion length of $\mathrm{Ru}$ adspecies based on the peak experimental nanoparticle density as $\lambda \approx 1 / \sqrt{\sum n}$, we find that $\lambda \approx 50 \mathrm{~nm}$ on $-\mathrm{OH}$ terminated $\mathrm{SiO}_{2}$ and $\lambda \approx 140 \mathrm{~nm}$ on $-\mathrm{CH}_{3}$-terminated $\mathrm{SiO}_{2}$. Such lengths are comparable to the nanoscale features of the $3 \mathrm{D}$ nanopatterns for which ASD approaches are developed. If we consider a patterned surface consisting of alternating bands of $\mathrm{SiO}_{2}$ and $\mathrm{TaN}$ or $\mathrm{TiN}$, it is reasonable to expect that if the distance $L$ between bands is smaller than $\lambda$, then nucleation would be effectively suppressed to a certain extent on the dielectrics because $\mathrm{TaN}$ or $\mathrm{TiN}$ would act as a sink for diffusing $\mathrm{Ru}$ adspecies. In particular, we would expect that for a given $L$, the gain in selectivity due to surface diffusion would be higher for $\mathrm{CH}_{3}$-terminated $\mathrm{SiO}_{2}$ than that for $\mathrm{OH}$-terminated $\mathrm{SiO}_{2}$.

Area-Selective Deposition from Space-Dependent Surface Diffusion. Informed by the role of surface diffusion in $\mathrm{Ru} C V D$, we investigate the possibility of achieving areaselective deposition as a result of changes in surface diffusion rates alone. As already mentioned, the boundary between 

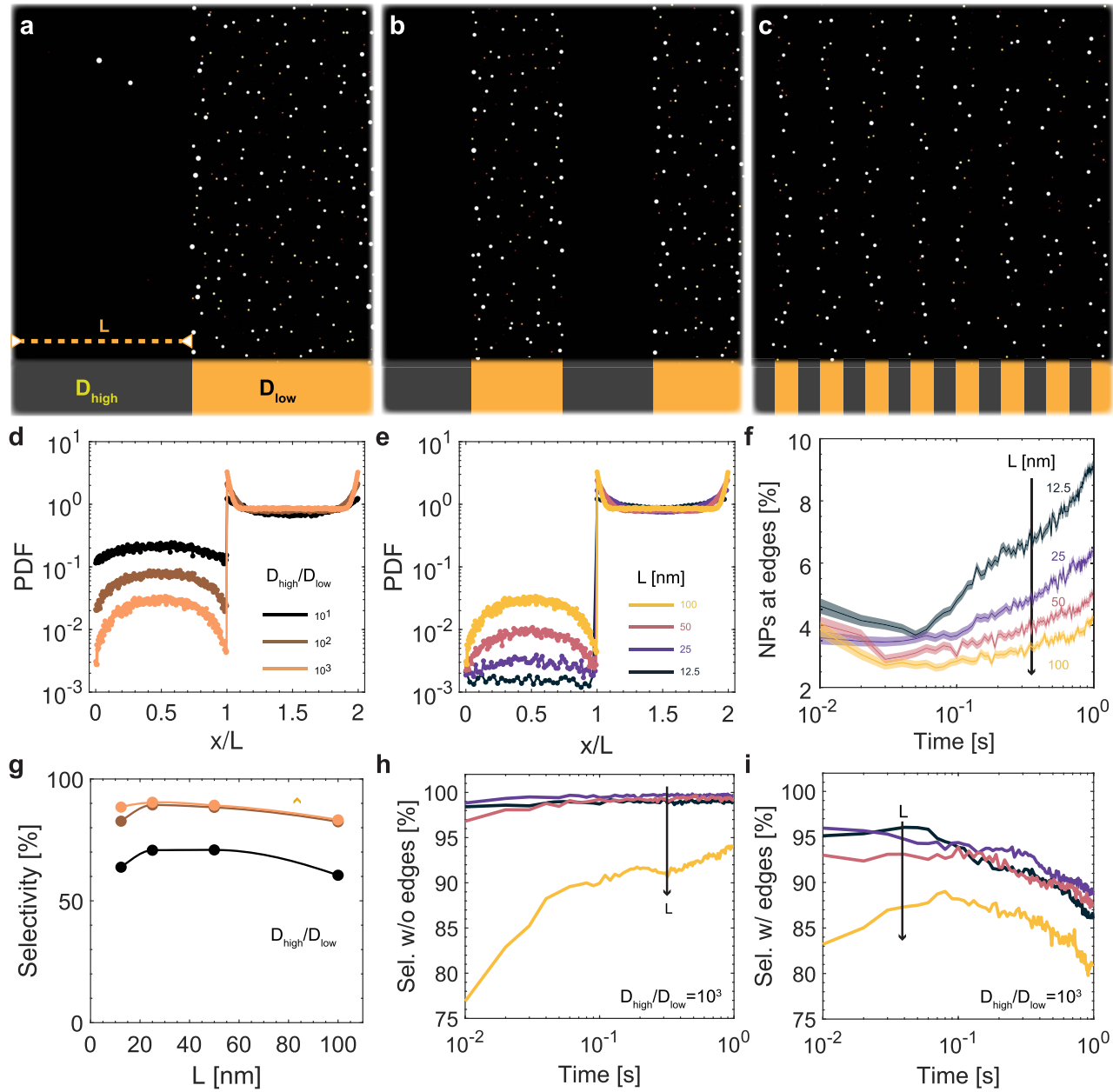

Figure 4. KMC simulations of island growth in the presence of space-dependent surface diffusivity. (a) - (c) Simulation snapshots taken after $1 \mathrm{~s}$ of deposition with $L$ equal to 100,50 , and $12.5 \mathrm{~nm}$, respectively. (d, e) Spatial distribution of the centers of mass of the nanoparticles within $D_{\text {high }}$ bands $(0 \leq x / L<1)$ and $D_{\text {low }}$ bands $(1 \leq x / L<2)$ during the first $1 \mathrm{~s}$ of deposition (based on 50 simulations for each case). (f) Evolution with time of the fraction of nanoparticles whose projected area intersects the edge between $D_{\text {high }}$ and $D_{\text {low }}$ bands. The shaded area denotes the $95 \%$ confidence intervals. (g) Time-averaged selectivity during the first $1 \mathrm{~s}$ of deposition. (h, i) Evolution with time of the selectivity calculated by excluding and including the nanoparticles straddling the edges between $D_{\text {high }}$ and $D_{\text {low }}$ bands, respectively.

nongrowth surfaces and growth surfaces can act as a sink for diffusing species, if these bind more strongly with the growth surface and if the diffusion rate is approximately zero on the growth surface. However, we further inquire as to whether a flux of adspecies can be sustained by a spatial gradient of surface diffusivity even with nonzero diffusivity and constant adsorption rates across the entire domain. To answer this question, we devised a series of lattice KMC simulations using a custom code written in Python, already described and validated in previous work, ${ }^{32}$ which is designed to simulate the same atomistic processes that are modeled with the mean-field model described here. In each simulation, we consider a square lattice that is divided into a sequence of alternating vertical bands of width $L$, with periodic boundary conditions enforced on each side. $G_{s}$ is constant throughout the entire lattice, while $D_{1}$ is constant within each band but changes from one band to the other from a high value $D_{\text {high }}$ to a low value $D_{\text {low }}$ in an alternating fashion (see Figure $4 \mathrm{a}-\mathrm{c}$ ).

We let $G_{\mathrm{s}}=0.4$ atom $\mathrm{nm}^{-2} \mathrm{~s}, G_{\mathrm{p}}=0.95$ atom nm $\mathrm{nm}^{-2} \mathrm{~s}, D_{\text {high }}=$ $10^{6} \mathrm{~nm}^{2} \mathrm{~s}^{-1}, \mathrm{H} / \mathrm{R}=1$, and $\alpha=1$. We then consider three different values of $D_{\text {low }}: 10^{-3} D_{\text {high }}, 10^{-2} D_{\text {high }}$, and $10^{-1} D_{\text {high }}$. For each of these cases, we also vary $L$ from 12.5 to $100 \mathrm{~nm}$. For each set of parameters, we ran 50 simulations with a $536 \times$
536 lattice up to $1 \mathrm{~s}$. It is worth pointing out that running simulations for experimentally relevant timescales (400 s) and with higher $D_{1}$ would require prohibitively long run times. The objective of these simulations is therefore not to try to reproduce experimental data but rather to explore the sole impact of surface diffusivity gradients on selectivity. We also remark that this would be a very daunting experimental task, as in physical systems one does not simply vary diffusion rates over orders of magnitude across a substrate in a seamless manner, especially without affecting adsorption rates too, hence the value of such in-silico experiments.

The KMC simulations clearly show that selective deposition can emerge from area-dependent diffusion rates (Figure 4), even when adsorption rates are constant over the substrate. Selectivity increases with the $D_{\text {high }} / D_{\text {low }}$ ratio and varies in a nonlinear fashion with $L$ (see Figure $4 \mathrm{~g}$ ). Here, selectivity is defined as

$$
\frac{M_{D_{\text {low }}}-M_{D_{\text {high }}}}{M_{D_{\text {low }}}+M_{D_{\text {high }}}}
$$




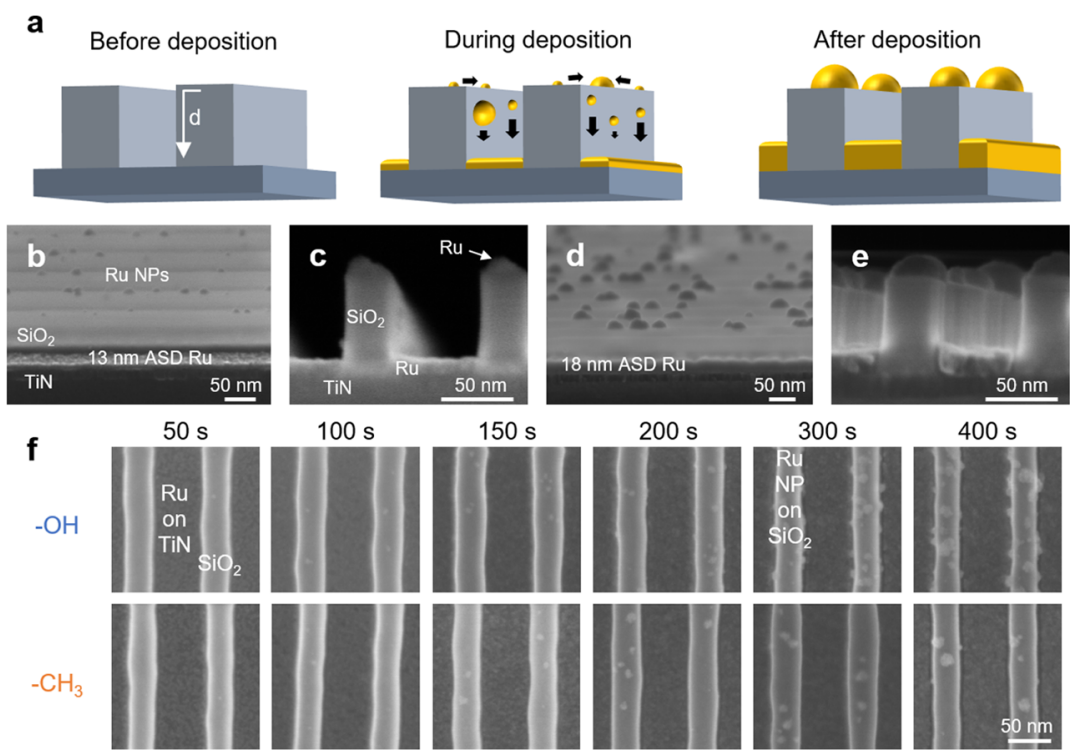

Figure 5. Morphology of $\mathrm{Ru}$ deposits after $\mathrm{Ru} \mathrm{CVD}\left(250{ }^{\circ} \mathrm{C}\right)$ on $\mathrm{TiN} / \mathrm{SiO}_{2}$ nanopatterns. (a) Schematic illustrating the proposed diffusionmediated mechanism for the enhancement of selectivity. The distance $\mathrm{d}$ corresponds to the maximum distance between any point on the $\mathrm{SiO}_{2}$ nongrowth surface and the nearest $\mathrm{TiN}$ growth surface. $(\mathrm{b}-\mathrm{e})$ Impact of $\mathrm{CVD}$ process conditions for a TiN growth surface and a $-\mathrm{CH}_{3}$-terminated $\mathrm{SiO}_{2}$ nongrowth surface. (b, c) Cross-sectional scanning electron microscopy (SEM) micrographs taken with the beam oriented perpendicular and parallel to the lines after $400 \mathrm{~s}$ of Ru CVD using $\mathrm{H}_{2}$ as the coreactant at 25 Torr reactor pressure, which is the same process as in Figures 2 and 3. (d, e) Cross-sectional SEM micrographs taken with the beam perpendicular and parallel to the lines after $400 \mathrm{~s}$ of $\mathrm{Ru}_{\mathrm{CVD}}$ using $\mathrm{NH}_{3}$ as the coreactant at 35 Torr reactor pressure, which results in thicker Ru films on TiN and larger Ru nanoparticles ( $\mathrm{NPs}$ ) on the $\mathrm{SiO}_{2}$ top surface. (f) Top-down SEM micrographs showing the impact of varying the composition of the nongrowth surface taken at different deposition times. The top rows and the bottoms rows correspond to $-\mathrm{OH}$ - and $-\mathrm{CH}_{3}$-terminated $\mathrm{SiO}_{2}$, respectively.

where $M_{D_{\text {low }}}$ and $M_{D_{\text {high }}}$ are the total numbers of atoms per unit of area in the regions of low and high surface diffusivity, respectively.

An analysis of the spatial distribution of the nanoparticles reveals that the nanoparticle density is higher in $D_{\text {low }}$ regions by up to three orders of magnitude depending on the $D_{\text {high }} /$ $D_{\text {low }}$ ratio (Figure $4 \mathrm{~d}$ ). Interestingly, the nanoparticle density is not constant throughout each region. Instead, it presents a peak in correspondence of the boundary between regions. Furthermore, the number density exhibits a concave profile across $D_{\text {low }}$ regions and a convex one across $D_{\text {high }}$ regions. In other words, next to the boundary on the $D_{\text {high }}$ side, there exists a depletion zone, whereas on the $D_{\text {low }}$ side, there is an accumulation zone. Furthermore, the smaller the width of the bands $L$, the flatter and the lower the density profile in the $D_{\text {high }}$ regions (Figure 4e). It is worth remarking that these results illustrate the value of KMC simulations, in that an experimental study of such gradients in the spatial distribution would require a prohibitively large body of microscopy data. $\mathrm{KMC}$ simulations can instead readily generate the large particle populations required to study such regularities.

The effective selectivity in $D_{\text {low }}$ regions can be explained by the fact that adspecies can quickly diffuse from low- to highdiffusivity regions, whereas the ones already in $D_{\text {low }}$ regions take longer to diffuse out. As a result, the number density of adspecies in $D_{\text {low }}$ regions initially increases, thus resulting in higher rates of nanoparticle formation and aggregation and of adatom capture. This in turn leads to the formation of larger and slower nanoparticles, which take even longer to diffuse out. Because the nanoparticle mobility drops quickly with size, this leads to the effective kinetic trapping of adspecies diffusing from high- to low-diffusivity regions. The higher number density in $D_{\text {low }}$ regions also translates into a higher metal surface area and thus into an overall higher growth rate, which further contributes to the degree of selectivity.

The flux of adspecies from $D_{\text {high }}$ to $D_{\text {low }}$ regions is also captured by an analysis of the fraction of nanoparticles straddling between regions (Figure 4f), that is, the ones next to the boundary in the $D_{\text {low }}$ side contributing to the peak in the spatial distribution (Figure $4 \mathrm{~d}-\mathrm{e}$ ). The fraction of such nanoparticles, in fact, increases with time and more so with smaller $L$. It follows that fast diffusing adspecies slow down upon entering $D_{\text {low }}$ regions and thus contribute to the formation and growth of slow-diffusing nanoparticles within an area right next to the edge between regions. Smaller values of $L$ then translate into shorter distances for the adspecies to cross before entering $D_{\text {low }}$ regions. A smaller $L$ also translates into a higher number of edges per unit area, hence the higher fraction of nanoparticles straddling the edges for smaller $L$.

Preferential growth in the proximity of the edges has an adverse effect on selectivity due to lateral growth. Although the center of mass of the nanoparticles tends to lie within $D_{\text {low }}$ regions, the nanoparticles next to the edge on the $D_{\text {low }}$ side can still grow large enough to cross into $D_{\text {high }}$ regions. This explains why the time-averaged selectivity can reach high values (>90\%) but tends to saturate in the limit of high $D_{\text {high }} / D_{\text {low }}$ ratios (Figure $4 \mathrm{~g}$ ). In fact, we find values of selectivity up to $100 \%$ throughout the simulation time when not accounting for the nanoparticles straddling the edges and for small values of $L$ (Figure $4 \mathrm{~h}-\mathrm{i}$ ). In the final analysis, away from the edges, the flux of adspecies between $D_{\text {high }}$ and $D_{\text {low }}$ regions can enable a selectivity up to $\sim 100 \%$; however, the preferential accumulation of material in the proximity of the edges reduces the overall selectivity over time due to the lateral growth of virtually immobile nanoparticles (Figure 4i). 
Ru CVD on 3D Nanopatterns. To investigate further the impact of surface diffusion in Ru ASD, we conducted Ru CVD experiments on $\mathrm{TiN} / \mathrm{SiO}_{2} 3 \mathrm{D}$ nanopatterns with $\mathrm{SiO}_{2}$ lines 37 $\mathrm{nm}$ wide and $70 \mathrm{~nm}$ high, yielding a maximum distance $d$ of 89 $\mathrm{nm}$ between any point on $\mathrm{SiO}_{2}$ and the nearest TiN surface (Figure 5a). This distance is intermediate between the adatom diffusion length on $-\mathrm{OH}$-terminated $(\sim 50 \mathrm{~nm})$ and $-\mathrm{CH}_{3}-$ terminated $(\sim 140 \mathrm{~nm}) \mathrm{SiO}_{2}$, thus making such patterns ideal candidates for studying the effect of surface diffusion on selectivity.

The morphology of Ru deposited after $400 \mathrm{~s}$ of CVD on a $\mathrm{TiN} /-\mathrm{CH}_{3}$-terminated $\mathrm{SiO}_{2}$ nanopattern $(\lambda>d)$ is shown in Figure $5 b-f$. Little to no $\mathrm{Ru}$ is observed on the $-\mathrm{CH}_{3}$ terminated $\mathrm{SiO}_{2}$ sidewalls of the nanopattern, indicating that $\mathrm{Ru}$ adspecies migrate toward the TiN growth surface, where they contribute to the growth of the Ru layer. In fact, the thickness of the latter $(13 \mathrm{~nm})$ is more than twice the thickness of films deposited on blanket TiN substrates under the same conditions (5.7 nm, Figure 2a), which is consistent with a diffusive flux of $\mathrm{Ru}$ adspecies contributing to the overall ASD growth rate. Nonetheless, despite such a flux, the Ru films on TiN appear relatively uniform in thickness, suggesting that $\mathrm{Ru}$ species reorganize themselves upon incorporation in the growing film to minimize the surface energy. This is expected given the high surface energy of $\mathrm{Ru}$. Such a material redistribution is advantageous for ASD as it results in a flat bottom-up fill of the $3 \mathrm{D}$ features.

Topography affects the growth kinetics on 3D nanopatterns and the spatial distribution of the $\mathrm{Ru}$ nanoparticles on the $\mathrm{SiO}_{2}$ lines. Contrary to the $\mathrm{SiO}_{2}$ sidewall, the $\mathrm{SiO}_{2}$ top surface is covered with $\mathrm{Ru}$ nanoparticles. Their size, ranging up to $20 \mathrm{~nm}$ after $400 \mathrm{~s}$ of deposition, suggests that diffusion and aggregation strongly contributed to their growth, as argued earlier. The smaller NP sizes compared to those on blanket $\mathrm{SiO}_{2}$ (Figure 2) could be attributed to the reduced $\mathrm{SiO}_{2}$ area surrounding each NP on patterns compared to that on blankets, meaning that fewer diffusing $\mathrm{Ru}$ adspecies are available in the NP vicinity. The fact that the sidewalls are virtually devoid of $\mathrm{Ru}$, while nanoparticles are observed on the top surface, suggests that the corner between the two surfaces impedes $\mathrm{Ru}$ adspecies migration from the top surface to the bottom growth surface. As Ru mobility is size-dependent, we cannot fully exclude the possibility that small adspecies can migrate over corners and that trapping is size-dependent. However, the hypothesis that the material deposited on the top surfaces cannot readily migrate and thus contribute to the growth of the film deposited on TiN is consistent with the observed thickness of the latter $(13 \mathrm{~nm})$. This can be shown by taking into account the relative contributions from each area to the total amount of Ru observed on TiN. Specifically, the ASD $\mathrm{Ru}$ growth rate on TiN has two contributions: (1) adsorption on the growing $\mathrm{Ru}$ film on $\mathrm{TiN}$ and (2) adsorption on $\mathrm{SiO}_{2}$ and subsequent diffusion toward the growing film. The adsorption rate on either $-\mathrm{OH}$ - or $-\mathrm{CH}_{3}$-terminated $\mathrm{SiO}_{2}$ contributes $4 \times 10^{13} \mathrm{Ru}$ atom $\mathrm{cm}^{-2} \mathrm{~s}^{-1}$, compared to $9 \times 10^{13}$ $\mathrm{Ru}$ atom $\mathrm{cm}^{-2} \mathrm{~s}^{-1}$ on $\mathrm{Ru}$. The adsorption rate on $\mathrm{SiO}_{2}$ is therefore 4/9 times the adsorption rate on $\mathrm{Ru}$. The amount of $\mathrm{Ru}$ observed on TiN lines $(13 \mathrm{~nm}$, Figure $5 \mathrm{~b}-\mathrm{c}$ ) corresponds to about 2.2 times the amount observed on blanket TiN substrates under the same conditions $(5.7 \mathrm{~nm}$, Figure $2 \mathrm{a})$. This means that adsorption on and subsequent diffusion from $\mathrm{SiO}_{2}$ areas surrounding each $\mathrm{TiN}$ line contribute 1.2 times as much $\mathrm{Ru}$ as adsorption on the $\mathrm{Ru}$ film itself (a factor 1 from $\mathrm{Ru}$ adsorption on $\mathrm{Ru}+1.2$ from $\mathrm{Ru}$ adsorption on and diffusion from $\mathrm{SiO}_{2}=$ a factor 2.2 for the total amount of $\mathrm{Ru}$ ). Assuming that the adsorption rate on $\mathrm{SiO}_{2}$ is $4 / 9^{\text {th }}$ the one on $\mathrm{TiN}$ and that all the $\mathrm{Ru}$ migrates from $\mathrm{SiO}_{2}$ to $\mathrm{TiN}$, the $\mathrm{SiO}_{2}$ to $\mathrm{TiN}$ area ratio that would explain the apparent adsorption rate on $\mathrm{TiN}$ is $1.2 /(4 / 9)=2.7$. For a TiN line width of $54 \mathrm{~nm}$, this corresponds to $146 \mathrm{~nm}$, which is closer to the height of two $\mathrm{SiO}_{2}$ sidewalls $(140 \mathrm{~nm})$ than to the sum of the height of the two sidewalls and the line width $(177 \mathrm{~nm})$.

The selectivity can be increased further by changing the CVD process conditions, specifically using $\mathrm{NH}_{3}$ rather than $\mathrm{H}_{2}$ as the coreagent and a reactor pressure of 35 Torr instead of 25 Torr (Figure $5 \mathrm{~d}-\mathrm{e}$ ). In this case, the top surface is covered with even larger particles, while no particles are observed on any of the sidewalls after $400 \mathrm{~s}$ deposition time. The larger nanoparticles and the thicker $\mathrm{Ru}$ film on TiN $(18 \mathrm{~nm})$ suggest that diffusion-mediated ASD can be promoted using different chemistries.

The impact of surface diffusion is greater on patterns with $-\mathrm{CH}_{3}$-terminated $\mathrm{SiO}_{2}(\lambda>d)$ than on those with $-\mathrm{OH}$ terminated $\mathrm{SiO}_{2}(\lambda<d)$. The evolution of the morphology of $\mathrm{Ru}$ deposits with deposition time is shown in Figure $5 \mathrm{f}$. $\mathrm{Ru}$ nanoparticles are observed on the sidewalls at later times on $-\mathrm{CH}_{3}$-terminated $\mathrm{SiO}_{2}$ than they do on $-\mathrm{OH}$-terminated $\mathrm{SiO}_{2}$. In particular, nanoparticles are observed on the sidewalls when the Ru film on TiN is about 7 and $13 \mathrm{~nm}$ thick on $-\mathrm{OH}$ and $-\mathrm{CH}_{3}$-terminated $\mathrm{SiO}_{2}$, respectively. Consequently, the highest selectivity is achieved for nanopatterns with $-\mathrm{CH}_{3}$ terminated $\mathrm{SiO}_{2}$. This agrees well with the diffusion length being larger on $-\mathrm{CH}_{3}$ terminated $\mathrm{SiO}_{2}$ than that on $-\mathrm{OH}$ terminated $\mathrm{SiO}_{2}$. This shows that a targeted surface modification, such as the DMA-TMS treatment used in this study, can promote ASD by primarily altering surface diffusion rates on the nongrowth surfaces.

\section{CONCLUSIONS}

Through a joint computational and experimental approach, we demonstrated the importance of surface diffusion and aggregation in $\mathrm{Ru} \mathrm{CVD}$ on $\mathrm{SiO}_{2}$ and its implications for area-selective deposition (ASD). We found that modifying the surface termination of $\mathrm{SiO}_{2}$ from $-\mathrm{OH}$ to $-\mathrm{CH}_{3}$, through the DMA-TMS surface treatment, changes the growth kinetics by affecting surface diffusion rates rather than adsorption rates.

Our results show that surface diffusion can be leveraged to reduce the extent of undesired deposition (defectivity) on nongrowth surfaces while enhancing the growth rate on growth surfaces. This is because deposits can migrate from highdiffusivity (nongrowth) to low-diffusivity (growth) surfaces during deposition. In this work, the reorganization of material upon aggregation is hardly kinetically limited, resulting in a flat profile of the selectively grown film rather than accumulation at the edges.

The diffusion length $\lambda$ on a given nongrowth surface, which can be estimated from the average distance between deposits at a steady state, provides a measure of the impact of surface diffusion on the selectivity on patterned substrates. Our findings suggest that nucleation can be effectively suppressed on $\mathrm{SiO}_{2}$ patches enclosed by metal surfaces if the distance from any point on the $\mathrm{SiO}_{2}$ surface to the $\mathrm{SiO}_{2}-$ metal boundary is $\lesssim \lambda$. We find that for $\mathrm{Ru}$ CVD on $\mathrm{SiO}_{2}, \lambda$ is comparable to the feature sizes (tens to hundreds of $\mathrm{nm}$ ) for which ASD is being developed. Studying the impact of surface termination and 
operating conditions on the diffusion length may therefore inform the development high-selectivity ASD processes.

Our findings have important implications for the interpretation of the experiments that are typically used to inform the design of new ASD processes. Because deposits can migrate from one surface to another on a patterned substrate, the selectivity on the latter is bound to be different from the one extrapolated from depositions performed on the individual surfaces, the so-called blankets. While deposition experiments on the latter can provide valuable insights into ASD, one should be wary of selectivity estimates based on blankets alone, not only when surface diffusion plays a role but also because of lateral overgrowth, especially for planar structures with nanoscale features. Furthermore, our experiments on 3D nanopatterns suggest that also topography, and in particular the presence of sharp corners, can affect surface diffusion and thus selectivity. The impact of topography therefore certainly merits further study.

Finally, the model-driven approach presented here, and in particular the use of population balance models expressing atomistic mechanisms, can be used to estimate quantities that are otherwise hard to access experimentally such as adsorption rates, diffusion coefficients, or the scaling of nanoparticle mobility. Knowing how such quantities vary as a function of operating conditions and of adlayer-substrate pairings is crucial to the design of tailored ASD processes based on thin film techniques such as chemical vapor deposition (CVD) and atomic layer deposition (ALD). In addition, our approach could be used to extract valuable data from large sets of experiments, which in turn could inform data-driven approaches based, for example, on machine learning. We therefore hope that this study will motivate further model- and data-driven investigations into the surface dependence of the elementary processes involved in ASD to enable a wider range of applications.

\section{EXPERIMENTAL AND COMPUTATIONAL METHODS}

Substrate Fabrication. Substrates for all deposition experiments were fabricated on $300 \mathrm{~mm} \mathrm{Si}(100)$ wafers. Substrates consist of TiN, $\mathrm{TaN}$, and $\mathrm{SiO}_{2}$ films, as well as $\mathrm{TiN} / \mathrm{SiO}_{2}$ nanopatterns. PVD TiN films $(15 \mathrm{~nm})$ were produced by sputtering a $\mathrm{Ti}$ target in a $\mathrm{N}_{2}$ ambiance. PVD TaN films $(3 \mathrm{~nm})$ were deposited by sputtering a Ta target in a $\mathrm{N}_{2}$ ambiance. $\mathrm{SiO}_{2}$ films $(15 \mathrm{~nm})$ were produced by PEALD, which produces a surface with $2.5-\mathrm{OH} \mathrm{nm}^{-2}$. ${ }^{32}$ The procedure for $\mathrm{TiN} / \mathrm{SiO}_{2}$ nanopattern fabrication is reported elsewhere and yields $54 \mathrm{~nm}$ trenches alternating with $37 \mathrm{~nm} \mathrm{SiO}$ lines. $^{48}$ The 70 $\mathrm{nm}$ deep trenches are etched in $\mathrm{SiO}_{2}$, exposing the TiN growth surface at the bottom of each trench. Some $\mathrm{SiO}_{2}$ substrates were treated with DMA-TMS at $250{ }^{\circ} \mathrm{C}$ for $300 \mathrm{~s}$ to produce a $\mathrm{Si}-\mathrm{CH}_{3}$ terminated $\mathrm{SiO}_{2}$ surface. ${ }^{18}$ Some of the $\mathrm{TiN} / \mathrm{SiO}_{2}$ nanopatterns were subject to a DMA-TMS treatment to obtain a well-defined $-\mathrm{CH}_{3 \text { - }}$ terminated $\mathrm{SiO}_{2}$ surface. ${ }^{48}$

Ru CVD Experiment. (Carbonyl) (alkylcyclohexadienyl) $\mathrm{Ru} / \mathrm{H}_{2}$ CVD was performed at $100-250{ }^{\circ} \mathrm{C}$ in a CVD reactor. $\mathrm{H}_{2}$ simultaneously flows to the reactor, and the pressure is kept at 25 Torr throughout the deposition. The TaN substrates are produced in situ before $\mathrm{Ru}$ CVD without intermediate air exposure in a PVD chamber connected to the same cluster as the CVD reactor.

Material Characterization. The surface energy of the surfaces treated with DMA-TMS was determined from water and diiodomethane contact angle measurements using the Van OssChaudhury-Good method. ${ }^{89-91}$ The contact angles measured right after sample preparation were found to be $100.7 \pm 0.5^{\circ}$ for water and $65.8 \pm 0.6^{\circ}$ for diiodomethane. These values correspond to polar and dispersive contributions to surface energy of 0.85 and $24 \mathrm{~mJ} \mathrm{~m}^{-2}$, respectively, amounting to a total surface energy of $0.03 \mathrm{~J} \mathrm{~m}^{-2}$. A suite of characterization techniques was used to investigate $\mathrm{Ru}$ growth on each substrate. The total amount of deposited Ru was measured by RBS using a $1.523 \mathrm{MeV} \mathrm{He}^{+}$incoming ion beam. The morphology of $\mathrm{Ru}$ layers and particle size distributions were investigated by SEM using an FEI Helios 460 microscope. To obtain particle size distributions, the radius of each particle was calculated from its area assuming a circular shape.

Uncertainty of the Fitting Parameters. To quantify the uncertainty of the estimated parameters $P_{i}$, we construct $95 \%$ confidence intervals as

$$
P_{i} \pm \sqrt{\sigma^{2}\left(J^{t} J\right)_{i i}^{-1}} t_{0.025, v}
$$

where $t_{0.025, v}$ is the critical value from the $t$-distribution with $v=n-p$ degrees of freedom, with $n$ and $p$ being the number of observations and parameters, respectively, $J$ is the Jacobian matrix with $J_{i j}=\frac{\partial y_{i}^{\text {sim }}}{\partial P_{j}}$, and $\sigma^{2}=\frac{1}{n-p} \sum_{i=1}^{n}\left(y_{i}^{\exp }-y_{i}^{\operatorname{sim}}(P)\right)^{2}$. The Jacobian was estimated numerically in the neighborhood of the estimated parameters using a fourth-order central finite-difference scheme.

\section{ASSOCIATED CONTENT}

\section{Supporting Information}

The Supporting Information is available free of charge at https://pubs.acs.org/doi/10.1021/acs.chemmater.0c02588.

Sensitivity of the simulated kinetics on the value of the adsorption rate on the substrate $\left(G_{s}\right)$ and on the $\mathrm{Ru}$ nanoparticles $\left(G_{\mathrm{p}}\right)$ on the predicted observables (PDF)

\section{AUTHOR INFORMATION}

\section{Corresponding Authors}

Fabio Grillo - Laboratory for Soft Materials and Interfaces, Department of Materials, ETH Zurich, Zurich 8093, Switzerland; 10 orcid.org/0000-0003-1486-3117; Email: fabio.grillo@mat.ethz.ch

Job Soethoudt - Department of Chemistry, KU Leuven (University of Leuven), 3001 Leuven, Belgium; IMEC, 3001 Leuven, Belgium; Email: jobsoethoudt@gmail.com

\section{Authors}

Esteban A. Marques - Department of Chemistry, KU Leuven (University of Leuven), 3001 Leuven, Belgium; IMEC, 3001 Leuven, Belgium

Lilian de Martín - Department of Chemical Engineering, Delft University of Technology, 2629 HZ Delft, The Netherlands; Radar Technology, TNO, 2597 The Hague, The Netherlands

Kaat Van Dongen - Department of Chemistry, KU Leuven (University of Leuven), 3001 Leuven, Belgium; IMEC, 3001 Leuven, Belgium

J. Ruud van Ommen - Department of Chemical Engineering, Delft University of Technology, $2629 \mathrm{HZ}$ Delft, The Netherlands; (i) orcid.org/0000-0001-7884-0323

Annelies Delabie - Department of Chemistry, KU Leuven (University of Leuven), 3001 Leuven, Belgium; IMEC, 3001 Leuven, Belgium; 이이이.org/0000-0001-9739-7419

Complete contact information is available at: https://pubs.acs.org/10.1021/acs.chemmater.0c02588

\section{Author Contributions}

All authors have given approval to the final version of the manuscript. F.G. and J.S. contributed equally. 


\section{Notes}

The authors declare no competing financial interest.

\section{ACKNOWLEDGMENTS}

This project has received funding from the Electronic Component Systems for European Leadership Joint Undertaking under grant agreement No. 692522.

\section{REFERENCES}

(1) Parsons, G. N.; Clark, R. D. Area-Selective Deposition: Fundamentals, Applications, and Future Outlook. Chem. Mater. 2020, 32, 4920-4953.

(2) Parsons, G. N. Functional model for analysis of ALD nucleation and quantification of area-selective deposition. J. Vac. Sci. Technol., A 2019, 37, No. 020911 .

(3) Bent, S. In Area Selective Atomic Layer Deposition for Advanced Nanofabrication, Abstracts of Papers of the American Chemical Society, 2019.

(4) Mackus, A. J. M.; Merkx, M. J. M.; Kessels, W. M. M. From the Bottom-Up: Toward Area-Selective Atomic Layer Deposition with High Selectivity. Chem. Mater. 2019, 31, 2-12.

(5) Gladfelter, W. L. Selective metallization process. Met. Finish. 1997, 95, 90-91.

(6) Carlsson, J. O. Principles of Area-Selective and Phase-Selective CVD on Patterned Substrates. High Temp. Sci. 1989, 27, 209-220.

(7) Cao, K.; Zhu, Q. Q.; Shan, B.; Chen, R. Controlled Synthesis of $\mathrm{Pd} / \mathrm{Pt}$ Core Shell Nanoparticles Using Area-selective Atomic Layer Deposition. Sci. Rep. 2015, 5, No. 8470.

(8) Cheng, N. C.; Banis, M. N.; Liu, J.; Riese, A.; Li, X.; Li, R. Y.; Ye, S. Y.; Knights, S.; Sun, X. L. Extremely Stable Platinum Nanoparticles Encapsulated in a Zirconia Nanocage by Area-Selective Atomic Layer Deposition for the Oxygen Reduction Reaction. Adv. Mater. 2015, 27, 277-281.

(9) Lee, H.-B.-R; Bent, S. F. A Selective Toolbox for Nanofabrication. Chem. Mater. 2020, 32, 3323-3324.

(10) Mohimi, E.; Zhang, Z. V.; Liu, S. M.; Mallek, J. L.; Girolami, G. S.; Abelson, J. R. Area selective CVD of metallic films from molybdenum, iron, and ruthenium carbonyl precursors: Use of ammonia to inhibit nucleation on oxide surfaces. J. Vac. Sci. Technol., A 2018, 36, No. 041507.

(11) Ryu, S. W.; Kim, S.; Yoon, J.; Tanskanen, J. T.; Kim, H.; Lee, H. B. R. Area-selective chemical vapor deposition of $\mathrm{Co}$ for $\mathrm{Cu}$ capping layer. Curr. Appl. Phys. 2016, 16, 88-92.

(12) Winter, C.; Weckenmann, U.; Fischer, R. A.; Kashammer, J.; Scheumann, V.; Mittler, S. Selective nucleation and area-selective OMCVD of gold on patterned self-assembled organic monolayers studied by AFM and XPS: A comparison of OMCVD and PVD. Chem. Vap. Deposition 2000, 6, 199-205.

(13) Tsubouchi, K.; Masu, K. Area-Selective Cvd of Metals. Thin Solid Films 1993, 228, 312-318.

(14) Balasubramanyam, S.; Merkx, M. J. M.; Verheijen, M. A.; Kessels, W. M. M.; Mackus, A. J. M.; Bol, A. A. Area-Selective Atomic Layer Deposition of Two-Dimensional WS2 Nanolayers. ACS Mater. Lett. 2020, 2, 511-518.

(15) Vos, M. F. J.; Chopra, S. N.; Verheijen, M. A.; Ekerdt, J. G.; Agarwal, S.; Kessels, W. M. M.; Mackus, A. J. M. Area-Selective Deposition of Ruthenium by Combining Atomic Layer Deposition and Selective Etching. Chem. Mater. 2019, 31, 3878-3882.

(16) Zyulkov, I.; Madhiwala, V.; Voronina, E.; Snelgrove, M.; Bogan, J.; O'Connor, R.; De Gendt, S.; Armini, S. Area-Selective ALD of Ru on Nanometer-Scale $\mathrm{Cu}$ Lines through Dimerization of AminoFunctionalized Alkoxy Silane Passivation Films. ACS Appl. Mater. Interfaces 2020, 12, 4678-4688.

(17) Merkx, M. J. M.; Sandoval, T. E.; Hausmann, D. M.; Kessels, W. M. M.; Mackus, A. J. M. Mechanism of Precursor Blocking by Acetylacetone Inhibitor Molecules during Area-Selective Atomic Layer Deposition of SiO2. Chem. Mater. 2020, 32, 3335-3345.
(18) Soethoudt, J.; Tomczak, Y.; Meynaerts, B.; Chan, B. T.; Delabie, A. Insight into Selective Surface Reactions of Dimethylamino-trimethylsilane for Area-Selective Deposition of Metal, Nitride, and Oxide. J. Phys. Chem. C 2020, 124, 7163-7173.

(19) Soethoudt, J.; Crahaij, S.; Conard, T.; Delabie, A. Impact of $\mathrm{SiO} 2$ surface composition on trimethylsilane passivation for areaselective deposition. J. Mater. Chem. C 2019, 7, 11911-11918.

(20) Bobb-Semple, D.; Nardi, K. L.; Draeger, N.; Hausmann, D. M.; Bent, S. F. Area-Selective Atomic Layer Deposition Assisted by SelfAssembled Monolayers: A Comparison of $\mathrm{Cu}, \mathrm{Co}, \mathrm{W}$, and $\mathrm{Ru}$. Chem. Mater. 2019, 31, 1635-1645.

(21) Lecordier, L.; Herregods, S.; Armini, S. Vapor-deposited octadecanethiol masking layer on copper to enable area selective Hf3N4 atomic layer deposition on dielectrics studied by in situ spectroscopic ellipsometry. J. Vac. Sci. Technol., A 2018, 36, No. 031605.

(22) Khan, R.; Shong, B.; Ko, B. G.; Lee, J. K.; Lee, H.; Park, J. Y.; Oh, I. K.; Raya, S. S.; Hong, H. M.; Chung, K. B.; Luber, E. J.; Kim, Y. S.; Lee, C. H.; Kim, W. H.; Lee, H. B. R. Area-Selective Atomic Layer Deposition Using Si Precursors as Inhibitors. Chem. Mater. 2018, 30, 7603-7610.

(23) Cummins, C.; Weingartner, T.; Morris, M. A. Enabling LargeArea Selective Deposition on Metal-Dielectric Patterns using Polymer Brush Deactivation. J. Phys. Chem. C 2018, 122, 14698-14705.

(24) Li, Z.; Van Gorp, H.; Walke, P.; Phan, T. H.; Fujita, Y.; Greenwood, J.; Ivasenko, O.; Tahara, K.; Tobe, Y.; Uji-I, H.; Mertens, S. F. L.; De Feyter, S. Area-selective passivation of $\mathrm{sp}(2)$ carbon surfaces by supramolecular self-assembly. Nanoscale 2017, 9, 51885193.

(25) Minaye Hashemi, F. S.; Prasittichai, C.; Bent, S. F. SelfCorrecting Process for High Quality Patterning by Atomic Layer Deposition. ACS Nano 2015, 9, 8710-8717.

(26) Chen, R.; Kim, H.; McIntyre, P. C.; Porter, D. W.; Bent, S. F. Achieving area-selective atomic layer deposition on patterned substrates by selective surface modification. Appl. Phys. Lett. 2005, 86, No. 191910.

(27) Cao, K.; Cai, J.; Chen, R. Inherently Selective Atomic Layer Deposition and Applications. Chem. Mater. 2020, 32, 2195-2207.

(28) Ratsch, C.; Venables, J. A. Nucleation theory and the early stages of thin film growth. J. Vac. Sci. Technol., A 2003, 21, S96-S109.

(29) Zhang, Z.; Lagally, M. G. Atomistic Processes in the Early Stages of Thin-Film Growth. Science 1997, 276, 377-383.

(30) Venables, J. A.; Spiller, G. D. T.; Hanbucken, M. Nucleation and growth of thin films. Rep. Prog. Phys. 1984, 47, 399-459.

(31) Grillo, F.; Bui, H. V.; Moulijn, J. A.; Kreutzer, M. T.; van Ommen, J. R. Understanding and Controlling the Aggregative Growth of Platinum Nanoparticles in Atomic Layer Deposition: An Avenue to Size Selection. J. Phys. Chem. Lett. 2017, 8, 975-983.

(32) Soethoudt, J.; Grillo, F.; Marques, E. A.; van Ommen, J. R.; Tomczak, Y.; Nyns, L.; Van Elshocht, S.; Delabie, A. DiffusionMediated Growth and Size-Dependent Nanoparticle Reactivity during Ruthenium Atomic Layer Deposition on Dielectric Substrates. Adv. Mater. Interfaces 2018, 5, No. 1800870.

(33) Grillo, F.; Van Bui, H.; La Zara, D.; Aarnink, A. A. I.; Kovalgin, A. Y.; Kooyman, P.; Kreutzer, M. T.; van Ommen, J. R. From Single Atoms to Nanoparticles: Autocatalysis and Metal Aggregation in Atomic Layer Deposition of Pt on TiO2 Nanopowder. Small 2018, 14, No. 1800765.

(34) Grillo, F.; Moulijn, J. A.; Kreutzer, M. T.; van Ommen, J. R. Nanoparticle sintering in atomic layer deposition of supported catalysts: Kinetic modeling of the size distribution. Catal. Today 2018, 316, 51-61

(35) Richey, N. E.; de Paula, C.; Bent, S. F. Understanding chemical and physical mechanisms in atomic layer deposition. J. Chem. Phys. 2020, 152, No. 040902.

(36) Dendooven, J.; Ramachandran, R. K.; Solano, E.; Kurttepeli, M.; Geerts, L.; Heremans, G.; Rongé, J.; Minjauw, M. M.; Dobbelaere, T.; Devloo-Casier, K.; Martens, J. A.; Vantomme, A.; Bals, S.; Portale, G.; Coati, A.; Detavernier, C. Independent tuning of 
size and coverage of supported $\mathrm{Pt}$ nanoparticles using atomic layer deposition. Nat. Commun. 2017, 8, No. 1074.

(37) Yanguas-Gil, A. Reactivity of heterogeneous surfaces: Modeling precursor-surface interaction using absorbing Markov chains. J. Vac. Sci. Technol., A 2018, 36, No. 051510.

(38) Yanguas-Gil, A. Impact of thermodynamic fluctuations and pattern size on the nucleation behavior during area selective deposition. J. Vac. Sci. Technol., A 2020, 38, No. 030401.

(39) Carlsson, J.-O. Selective vapor-phase deposition on patterned substrates. Crit. Rev. Solid State Mater. Sci. 1990, 16, 161-212.

(40) Bartelt, M. C.; Evans, J. W. Scaling analysis of diffusionmediated island growth in surface adsorption processes. Phys. Rev. B 1992, 46, 12675-12687.

(41) Venables, J. A. Rate Equation Approaches to Thin-Film Nucleation Kinetics. Philos. Mag. 1973, 27, 697-738.

(42) Solano, E.; Dendooven, J.; Minjauw, M. M.; Ramachandran, R. K.; Van de Kerckhove, K.; Dobbelaere, T.; Hermida-Merino, D.; Detavernier, C. Key role of surface oxidation and reduction processes in the coarsening of Pt nanoparticles. Nanoscale 2017, 9, 18109.

(43) Lai, K. C.; Han, Y.; Spurgeon, P.; Huang, W.; Thiel, P. A.; Liu, D. J.; Evans, J. W. Reshaping, Intermixing, and Coarsening for Metallic Nanocrystals: Nonequilibrium Statistical Mechanical and Coarse-Grained Modeling. Chem. Rev. 2019, 119, 6670-6768.

(44) Wynblatt, P.; Gjostein, N. A. Supported metal crystallites. Prog. Solid State Chem. 1975, 9, 21-58.

(45) Färm, E.; Lindroos, S.; Ritala, M.; Leskelä, M. Microcontact Printed $\mathrm{RuO}_{x}$ Film as an Activation Layer for Selective-Area Atomic Layer Deposition of Ruthenium. Chem. Mater. 2012, 24, 275-278.

(46) Vasilyev, V. Y.; Mogilnikov, K. P.; Song, Y. W. Surface Selective Growth of Ruthenium Films under Low-Temperature Pulsed CVD Conditions. Electrochem. Solid-State Lett. 2008, 11, No. D89.

(47) Park, K. J.; Doub, J. M.; Gougousi, T.; Parsons, G. N. Microcontact patterning of ruthenium gate electrodes by selective area atomic layer deposition. Appl. Phys. Lett. 2005, 86, No. 051903.

(48) Soethoudt, J.; Hody, H.; Spampinato, V.; Franquet, A.; Briggs, B.; Chan, B. T.; Delabie, A. Defect Mitigation in Area-Selective Atomic Layer Deposition of Ruthenium on Titanium Nitride/ Dielectric Nanopatterns. Adv. Mater. Interfaces 2019, 6, No. 1900896.

(49) Zyulkov, I.; Krishtab, M.; De Gendt, S.; Armini, S. Selective Ru ALD as a Catalyst for Sub-Seven-Nanometer Bottom-Up Metal Interconnects. ACS Appl. Mater. Interfaces 2017, 9, 31031-31041.

(50) Vos, M. F. J.; Chopra, S. N.; Verheijen, M. A.; Ekerdt, J. G.; Agarwal, S.; Kessels, W. M. M.; Mackus, A. J. M. Area-Selective Deposition of Ruthenium by Combining Atomic Layer Deposition and Selective Etching. Chem. Mater. 2019, 31, 3878-3882.

(51) Wen, L. G.; Roussel, P.; Pedreira, O. V.; Briggs, B.; Groven, B.; Dutta, S.; Popovici, M. I.; Heylen, N.; Ciofi, I.; Vanstreels, K.; Osterberg, F. W.; Hansen, O.; Petersen, D. H.; Opsomer, K.; Detavernier, C.; Wilson, C. J.; Elshocht, S. V.; Croes, K.; Bommels, J.; Tokei, Z.; Adelmann, C. Atomic Layer Deposition of Ruthenium with TiN Interface for Sub-10 nm Advanced Interconnects beyond Copper. ACS Appl. Mater. Interfaces 2016, 8, 26119-26125.

(52) Alyami, N. M.; Lagrow, A. P.; Joya, K. S.; Hwang, J.; Katsiev, K.; Anjum, D. H.; Losovyj, Y.; Sinatra, L.; Kim, J. Y.; Bakr, O. M. Tailoring ruthenium exposure to enhance the performance of fcc platinum@ruthenium core-shell electrocatalysts in the oxygen evolution reaction. Phys. Chem. Chem. Phys. 2016, 18, 16169-16178.

(53) Yang, C. C.; McFeely, F. R.; Wang, P. C.; Chanda, K.; Edelstein, D. C. Selective Chemical Vapor Deposition-Grown Ru for $\mathrm{Cu}$ Interconnect Capping Applications. Electrochem. Solid-State Lett. 2010, 13, D33-D35.

(54) Logothetidis, S.; Meletis, E. I.; Stergioudis, G.; Adjaottor, A. A. Room temperature oxidation behavior of TiN thin films. Thin Solid Films 1999, 338, 304-313.

(55) Puurunen, R. L. Growth Per Cycle in Atomic Layer Deposition: Real Application Examplesof a Theoretical Model. Chem. Vap. Deposition 2003, 9, 327-332.
(56) Li, Z.; Rahtu, A.; Gordon, R. G. Atomic Layer Deposition of Ultrathin Copper Metal Films from a Liquid Copper(I) Amidinate Precursor. J. Electrochem. Soc. 2006, 153, No. C787.

(57) Vitos, L.; Ruban, A. V.; Skriver, H. L.; Kollár, J. The surface energy of metals. Surf. Sci. 1998, 411, 186-202.

(58) Miskiewicz, P.; Kotarba, S.; Jung, J.; Marszalek, T.; MasTorrent, M.; Gomar-Nadal, E.; Amabilino, D. B.; Rovira, C.; Veciana, J.; Maniukiewicz, W.; Ulanski, J. Influence of $\mathrm{SiO} 2$ surface energy on the performance of organic field effect transistors based on highly oriented, zone-cast layers of a tetrathiafulvalene derivative. J. Appl. Phys. 2008, 104, No. 054509.

(59) Eremin, E. N.; Yurov, V. M.; Laurynas, V. C.; Guchenko, S. A.; Kasymov, S. S. Method for determining the surface energy of nitrides, carbides and borides. J. Phys.: Conf. Ser. 2019, 1210, No. 012041.

(60) Diebold, U. The surface science of titanium dioxide. Surf. Sci. Rep. 2003, 48, 53-229.

(61) Hubartt, B. C.; Kryukov, Y. A.; Amar, J. G. Rate-equation approach to irreversible island growth with cluster diffusion. Phys. Rev. E 2011, 84, No. 021604.

(62) Sholl, D. S.; Skodje, R. T. Late-stage coarsening of adlayers by dynamic cluster coalescence. Phys. A 1996, 231, 631-647.

(63) Kryukov, Y. A.; Amar, J. G. Effects of cluster diffusion on the island density and size distribution in submonolayer island growth. Phys. Rev. E 2011, 83, No. 041611.

(64) Jensen, P. Growth of nanostructures by cluster deposition: Experiments and simple models. Rev. Mod. Phys. 1999, 71, 16951735.

(65) Plessow, P. N.; Abild-Pedersen, F. Sintering of Pt Nanoparticles via Volatile PtO2: Simulation and Comparison with Experiments. ACS Catal. 2016, 6, 7098-7108.

(66) Goodman, E. D.; Schwalbe, J. A.; Cargnello, M. Mechanistic Understanding and the Rational Design of Sinter-Resistant Heterogeneous Catalysts. ACS Catal. 2017, 7, 7156-7173.

(67) Wan, Q.; Hu, S.; Dai, J.; Chen, C.; Li, W.-X. Influence of Crystal Facet and Phase of Titanium Dioxide on Ostwald Ripening of Supported Pt Nanoparticles from First-Principles Kinetics. J. Phys. Chem. C 2019, 123, 11020-11031.

(68) Wynblatt, P.; Gjostein, N. A. Particle growth in model supported metal catalysts-I. Theory. Acta Metall. 1976, 24, 11651174.

(69) Talapin, D. V.; Rogach, A. L.; Haase, M.; Weller, H. Evolution of an Ensemble of Nanoparticles in a Colloidal Solution: Theoretical Study. J. Phys. Chem. B 2001, 105, 12278-12285.

(70) Zinke-Allmang, M.; Feldman, L. C.; Grabow, M. H. Clustering on surfaces. Surf. Sci. Rep. 1992, 16, 377-463.

(71) Harris, P. J. F. Growth and structure of supported metal catalyst particles. Int. Mater. Rev. 1995, 40, 97-115.

(72) Simonsen, S. B.; Chorkendorff, I.; Dahl, S.; Skoglundh, M.; Sehested, J.; Helveg, S. Direct Observations of Oxygen-induced Platinum Nanoparticle Ripening Studied by In Situ TEM. J. Am. Chem. Soc. 2010, 132, 7968-7975.

(73) Prestat, E.; Popescu, R.; Blank, H.; Schneider, R.; Gerthsen, D. Coarsening of $\mathrm{Pt}$ nanoparticles on amorphous carbon film. Surf. Sci. 2013, 609, 195-202.

(74) Gladfelter, W. L. Selective metalization by chemical vapor deposition. Chem. Mater. 1993, 5, 1372-1388.

(75) Harsdorff, M. The influence of charged point defects and contamination of substrate surfaces on nucleation. Thin Solid Films 1984, 116, 55-74.

(76) Bouchaud, J. P.; Georges, A. Anomalous Diffusion in Disordered Media - Statistical Mechanisms, Models and Physical Applications. Phys. Rep. 1990, 195, 127-293.

(77) Jak, M. J. J.; Konstapel, C.; van Kreuningen, A.; Verhoeven, J.; Frenken, J. W. M. Scanning tunnelling microscopy study of the growth of small palladium particles on TiO2(110). Surf. Sci. 2000, 457, 295-310.

(78) Jak, M. J. J.; Konstapel, C.; van Kreuningen, A.; Chrost, J.; Verhoeven, J.; Frenken, J. W. M. The influence of substrate defects on 
the growth rate of palladium nanoparticles on a $\mathrm{TiO} 2(110)$ surface. Surf. Sci. 2001, 474, 28-36.

(79) Hubartt, B. C.; Kryukov, Y. A.; Amar, J. G. Rate-equation approach to irreversible island growth with cluster diffusion. Phys. Rev. E 2011, 84, No. 021604.

(80) Li, L.; Plessow, P. N.; Rieger, M.; Sauer, S.; Sanchez-Carrera, R. S.; Schaefer, A.; Abild-Pedersen, F. Modeling the Migration of Platinum Nanoparticles on Surfaces Using a Kinetic Monte Carlo Approach. J. Phys. Chem. C 2017, 121, 4261-4269.

(81) Pai, W. W.; Swan, A. K.; Zhang, Z.; Wendelken, J. F. Island diffusion and coarsening on metal (100) surfaces. Phys. Rev. Lett. 1997, 79, 3210-3213.

(82) Bell, G. R.; Dawson, P. M.; Pandey, P. A.; Wilson, N. R.; Mulheran, P. A. Size-dependent mobility of gold nano-clusters during growth on chemically modified graphene. APL Mater. 2014, 2, No. 012109.

(83) Winkler, K.; Wojciechowski, T.; Liszewska, M.; Gorecka, E.; Fialkowski, M. Morphological changes of gold nanoparticles due to adsorption onto silicon substrate and oxygen plasma treatment. RSC Adv. 2014, 4, 12729-12736.

(84) Kumar, S.; Ramkrishna, D. On the solution of population balance equations by discretization - III. Nucleation, growth and aggregation of particles. Chem. Eng. Sci. 1997, 52, 4659-4679.

(85) Kumar, S.; Ramkrishna, D. On the solution of population balance equations by discretization. 2. A moving pivot technique. Chem. Eng. Sci. 1996, 51, 1333-1342.

(86) Kumar, S.; Ramkrishna, D. On the solution of population balance equations by discretization. 1. A fixed pivot technique. Chem. Eng. Sci. 1996, 51, 1311-1332.

(87) Morley, S. K.; Brito, T. V.; Welling, D. T. Measures of Model Performance Based On the Log Accuracy Ratio. Space Weather 2018, $16,69-88$.

(88) Seebauer, E. G.; Allen, C. E. Estimating Surface-Diffusion Coefficients. Prog. Surf. Sci. 1995, 49, 265-330.

(89) Van Oss, C. J.; Chaudhury, M. K.; Good, R. J. Interfacial Lifshitz-van der Waals and polar interactions in macroscopic systems. Chem. Rev. 1988, 88, 927-941.

(90) Good, R. J.; van Oss, C. J. The Modern Theory of Contact Angles and the Hydrogen Bond Components of Surface Energies. In Modern Approaches to Wettability; Springer, 1992; pp 1-27.

(91) Good, R. J. Contact angle, wetting, and adhesion: a critical review. J. Adhes. Sci. Technol. 1992, 6, 1269-1302. 